\title{
Examination of Strength Modeling Reliability of Physical Tests on Structural Concrete Columns
}

\author{
Sher Ali Mirza \\ Civil Engineering, Lakehead University, Thunder Bay, ON, Canada P7B 5E1 \\ Correspondence should be addressed to Sher Ali Mirza, samirza@lakeheadu.ca \\ Received 28 July 2010; Accepted 20 February 2011 \\ Academic Editor: Bassam A. Izzuddin
}

Copyright () 2011 Sher Ali Mirza. This is an open access article distributed under the Creative Commons Attribution License, which permits unrestricted use, distribution, and reproduction in any medium, provided the original work is properly cited.

Comparisons and analyses of strengths from selected computational procedures were undertaken of more than 500 physical tests of rectangular, tied, structural concrete columns reported in the published literature. The computational procedures compared with the physical tests and with each other include a commercially available nonlinear finite element modeling software and the Canadian Standards Association (CSA) Standard A23.3-04. The requirements of the American Concrete Institute (ACI) 318-08 are very similar to those of the CSA A23.3-04, and hence, strength comparisons and analyses reported here are also applicable to ACI 318-08. The physical tests used for comparison were conducted on columns that were braced and pinned at both ends and were constructed using normal-density concrete with a compressive strength between approximately 17 and $57 \mathrm{MPa}$. The columns were subjected to short-term loads producing pure axial force, axial force combined with symmetrical single-curvature bending, or pure bending. Major variables included the concrete strength, the end eccentricity ratio, the slenderness ratio, the longitudinal reinforcing steel index for reinforced concrete or the structural steel index for composite columns, and the transverse reinforcement (tie/hoop) volumetric ratio. The study provides an examination of the reliability of the computational methods examined.

\section{Introduction}

In 1981, Furlong [1] advocated that considerable time in engineering design offices could be saved if structural analysis computer software were used to compute secondorder or frame slenderness effects. Since then, several such computer programs have been developed. During the past 15 to 20 years, however, finite element modeling (FEM) software has become more readily available, and its use by structural design engineers has been steadily increasing. Presently, there are several FEM programs that are able to model the structural concrete column behavior and strength. Similarly, during the past couple of decades, structural systems that employ composite columns consisting of steel shapes encased in concrete have been economically used in the construction of tall buildings [2]. The concrete used for encasing a structural steel section not only increases its strength and stiffness, but also protects it from the fire damage. As a result, the use of composite columns is on the rise in building construction in addition to applications in marine structures. To examine the accuracy of FEM in computing the strength of reinforced concrete columns and of composite steel-concrete columns in which steel sections are encased in concrete, the results from 504 physical tests taken from the published literature were compared with those obtained from a nonlinear FEM software [3, 4]. In addition, the strengths obtained from FEM and from the physical tests were compared with the strengths computed from CSA A23.3-04 [5] and are reported in this paper. Of the physical tests used, 354 were conducted on reinforced concrete columns reported in 25 investigations, while the remaining 150 were conducted on concrete-encased steel composite columns reported in eight investigations. The study included only those column tests for which the complete information required for both computational methods was available from the published data. The requirements of the American Concrete Institute (ACI) 318-08 [6] are very similar to those of the CSA A23.3-04, and, hence strength comparisons and analyses reported here are also applicable to ACI 318-08.

The physical tests were conducted on rectangular tied columns that were braced and pin ended at both ends 


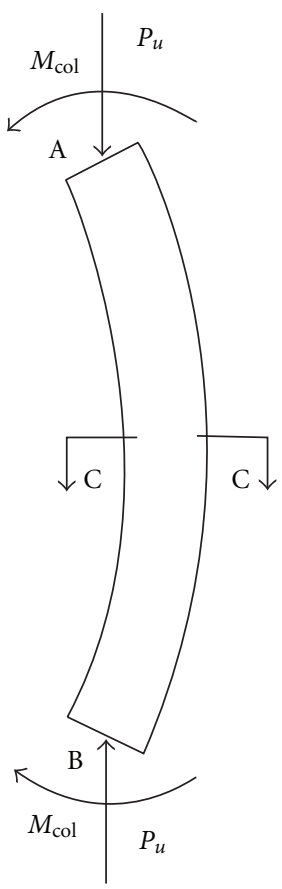

(a)

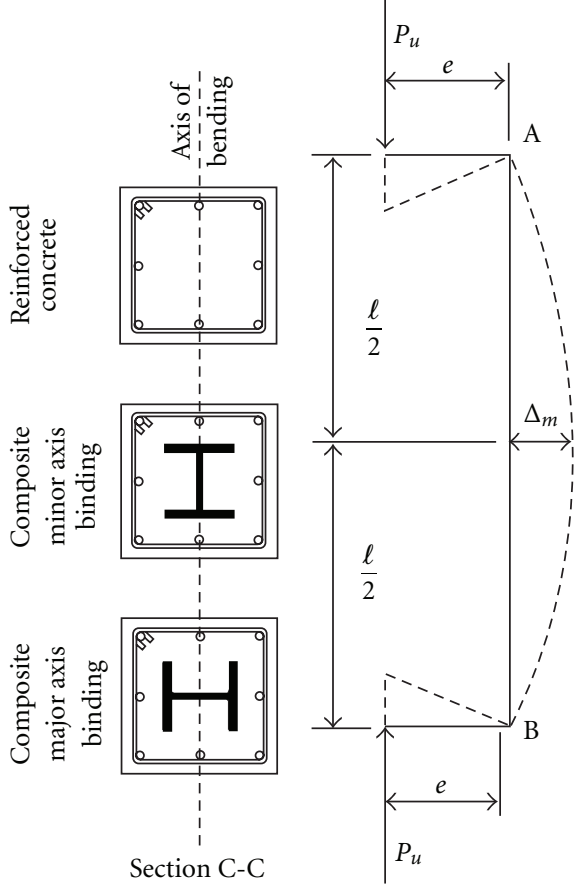

(c)

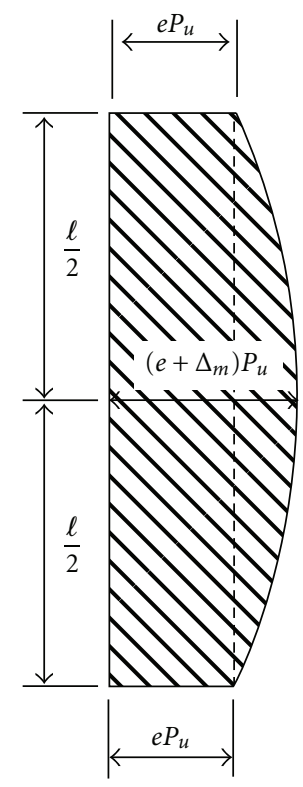

(d)

Figure 1: Type of columns studied: (a) free-body diagram of pin-ended column in symmetrical single-curvature bending, (b) schematic cross-sections, (c) forces on column, and (d) bending moment diagram $\left(M_{\mathrm{col}}=e P_{u} ; M_{\mathrm{cs}}=\left(e+\Delta_{m}\right) P_{u}\right)$.

and were constructed using normal-density concrete with a compressive strength between approximately 17 and $57 \mathrm{MPa}$. The columns were subjected to short-term loads producing pure axial force, combined axial force and symmetrical single-curvature bending, or pure bending. A graphical representation of the columns investigated is given in Figure 1. In Figure $1, P_{u}$ is the axial load strength, $M_{\mathrm{col}}$ and $M_{\mathrm{cs}}$ are the bending moment strength of a column (member) and that of a column cross-section, respectively, at an axial load equal to $P_{u}$, and $\Delta_{m}$ is the lateral deflection of the column at midlength.

Major variables investigated in this study include the concrete strength $f_{c}^{\prime}$, the end eccentricity ratio $e / h$, the slenderness ratio $\ell / h$, the longitudinal reinforcing steel index $\rho_{r s} f_{y r s} / f_{c}^{\prime}$ for reinforced concrete columns or the structural steel index $\rho_{s s} f_{y s s} / f_{c}^{\prime}$ for composite columns, and the transverse reinforcement (tie/hoop) volumetric ratio $\rho^{\prime \prime}$ taken equal to $2\left(b^{\prime \prime}+d^{\prime \prime}\right) A_{t} / b^{\prime \prime} d^{\prime \prime} s_{h}$, where $e=$ eccentricity of the axial load at column ends, $h=$ overall depth of the flexural rigidity area taken perpendicular to the axis of bending, $\ell=$ unbraced length of the column, $f_{y r s}=$ yield strength of the longitudinal reinforcing steel bars, $f_{y s s}=$ yield strength of structural steel, $\rho_{r s}=$ ratio of the crosssectional area of longitudinal reinforcing bars to the gross flexural rigidity area (longitudinal reinforcing steel ratio), $\rho_{s s}=$ ratio of the cross-sectional area of the structural steel section to the gross flexural rigidity area (structural steel ratio), $A_{t}=$ cross-sectional area of a tie/hoop bar, $b^{\prime \prime}=$ outside width of ties/hoops, $d^{\prime \prime}=$ outside depth of ties/hoops, and $s_{h}=$ spacing of ties/hoops. Evaluations of major variables affecting the strength were based on statistical analyses of the ratios of tested strengths to computed FEM or CSA strengths (strength ratios). These evaluations, plus the comparisons of tested and computed strengths, provide insights for the critical review of the reliability and related statistics of the computational methods examined and are presented and discussed in detail in this paper. The strength comparisons and statistical evaluations will be useful to structural engineers using FEM and/or CSA methods for design of structural concrete columns. As the column specimens were constructed with normal-density, normal-strength concrete with compressive strengths between 17 and $57 \mathrm{MPa}$ and subjected to short-term loads, the results of the study are limited to such columns.

\section{Summary of Physical Tests}

The experimental results used in this study for rectangular, tied, and reinforced concrete column specimens were taken from 354 short-term physical tests reported by Bresler [7], Bresler and Gilbert [8], Bunni [9], Chang and Ferguson [10], Cusson and Paultre [11], Drysdale and Huggins [12], Ernst et al. [13], Fang et al. [14], Gaede [15], Goyal and Jackson [16], Green and Hellesland [17], Heimdahl and Bianchini [18], Hognestad [19], Hudson [20], Kim and Yang [21], Martin and Olivieri [22], Mehmel et al. [23], Pfister [24], Ramu et al. [25], Razvi and Saatcioglu [26], Roy and Sozen [27], Scott et al. [28], Sheikh and Uzumeri [29], Todeschini et al. [30], and Viest et al. [31]. Of these test specimens, 163 were subjected to pure axial load, and the remaining 191 were subjected 
TABLE 1: Summary of geometric and material properties of reinforced concrete column specimens $\mathrm{s}^{\mathrm{a}}$.

\begin{tabular}{lcc}
\hline Properties & Minimum values & Maximum values \\
\hline$b \times h(\mathrm{~mm} \times \mathrm{mm})$ & $76 \times 76$ & $450 \times 450$ \\
$f_{c}^{\prime}(\mathrm{MPa})$ & 17.6 & 56.9 \\
$e / h$ & 0.00 & 1.25 \\
$\ell / h$ & 2.0 & 40.0 \\
$f_{\text {yrs }}(\mathrm{MPa})$ & 272.4 & 720.5 \\
$\rho_{\mathrm{rs}}(\%)$ & 0.80 & 7.06 \\
$\rho^{\prime \prime}(\%)$ & 0.04 & 4.73 \\
\hline
\end{tabular}

${ }^{\mathrm{a}}$ Number of specimens $=354$.

TABle 2: Summary of geometric and material properties of composite column specimens ${ }^{\mathrm{a}}$.

\begin{tabular}{lcc}
\hline Properties & Minimum values & Maximum values \\
\hline$b \times h(\mathrm{~mm} \times \mathrm{mm})$ & $160 \times 160$ & $406 \times 305$ \\
$f_{c}^{\prime}(\mathrm{MPa})$ & 17.4 & 55.8 \\
$e / h$ & 0.00 & $1.06^{\mathrm{a}}$ \\
$\ell / h$ & 2.0 & 28.9 \\
$f_{\text {yss }}(\mathrm{MPa})$ & 227.0 & 783.9 \\
$f_{\text {yrs }}(\mathrm{MPa})$ & 220.0 & 420.0 \\
$\rho_{\mathrm{ss}}(\%)$ & 2.70 & 14.45 \\
$\rho_{\mathrm{rs}}(\%)$ & 0.00 & 3.14 \\
$\rho^{\prime \prime}(\%)$ & 0.00 & 2.91 \\
\hline
\end{tabular}

${ }^{a}$ Number of specimens $=150$ of which 16 tested in pure bending $(e / h=\infty)$.

to axial load combined with symmetrical single-curvature bending. The geometric and material properties of the reinforced concrete test specimens are summarized in Table 1 and cover rather large ranges of the column cross-section size $(b \times h)$ and other variables investigated. Note that in Table $1, b$ is defined as the overall width of the cross-section parallel to the axis of bending. The experimental data used in this study for rectangular, tied, and composite column specimens were taken from 150 short-term physical tests reported by Anslijn and Janss [32], Morino et al. [33], Procter [34], Roderick and Loke [35], Roik and Mangerig [36], Roik and Schwalbenhofer [37], Stevens [38], and Suzuki et al. [39]. These tests were conducted on composite column specimens with steel sections encased in concrete. Of these test specimens, 58 were subjected to pure axial load, 76 were subjected to axial load combined with symmetrical single curvature bending, and the remaining 16 were subjected to pure bending. Note that the specimens tested under pure bending had cross-sectional details normally used for columns and were included in this study so that the entire axial load-bending moment interaction diagram could be investigated. The geometric and material properties of the composite test specimens are summarized in Table 2 and cover large ranges of the variables investigated. The physical failure strength of a column specimen was defined as the peak strength reached on the load-deflection or momentdeflection response curve.

In this study, the concrete strength $f_{c}^{\prime}$ was defined as the strength obtained from the tests conducted on standard 150-mm diameter by $300-\mathrm{mm}$ high cylinders or as the equivalent standard cylinder strength computed from cube tests. For some of the physical tests, the cube test strengths were reported. In such cases, the reported strengths were converted to the equivalent standard cylinder strengths by using the following procedure documented by Mirza et al. [40]. The strength of a cube of a given size was first converted to the strength of a $100-\mathrm{mm}$ cube, and this strength of the $100-\mathrm{mm}$ cube was then converted to the strength of a 150$\mathrm{mm}$ cube. An equation based on the statistical theory of brittle fracture of solids and proposed by Bolotin [41] was used for this purpose

$$
f=f_{o}\left[0.58+0.42\left(\frac{v_{o}}{v}\right)^{1 / 3}\right],
$$

in which $f_{o}$ and $v_{o}$ are the concrete strength and volume of a $100-\mathrm{mm}$ cube, and $f$ and $v$ represent the concrete strength and volume of the cube of a given size. Once the strength of an equivalent $150-\mathrm{mm}$ concrete cube was obtained, it was converted to the equivalent strength of a standard cylinder by using an equation proposed by L'Hermite [42]

$$
f_{c}^{\prime}=\left[0.76+0.2 \log _{10}\left(\frac{f_{\mathrm{cu}}}{19.6}\right)\right] f_{\mathrm{cu}}
$$

in which $f_{\text {cu }}$ is the strength of a $150-\mathrm{mm}$ cube in MPa.

The longitudinal reinforcing and structural steel yield strengths $\left(f_{\mathrm{yrs}}\right.$ and $\left.f_{\mathrm{yss}}\right)$ were taken as those for bar and coupon sample tests reported in individual studies available from the literature. The transverse reinforcement yield strengths were not reported for the majority of tests examined. In those cases, the yield strength of transverse reinforcement was assumed to be equal to the yield strength of longitudinal reinforcing bars.

\section{Description of Finite Element Modeling (FEM)}

The FEM of strengths and load-deflection responses (moment-deflection responses in cases of pure bending) for test columns was carried out by using a nonlinear FEM software $[3,4]$. The software was capable of performing static second-order strength analysis involving both material and geometric nonlinearities. No material and/or member resistance factors were applied to computed strengths and loaddeflection (or moment-deflection) responses. The computed FEM strengths, therefore, represent the unfactored strengths in this study.

The FEM software included an extensive library of predefined rebar elements and three-dimensional beam (space) sections that were used. This greatly simplified the data input required to model the reinforced concrete as well as composite cross-sections. A composite cross-section was assumed to consist of four different materials, each represented by a different stress-strain curve. These materials include (a) the unconfined concrete outside the transverse tie reinforcement, (b) the partially confined concrete within the transverse ties; (c) the longitudinal reinforcing steel bars, 


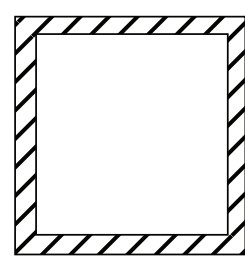

(a) Unconfined concrete

$+$

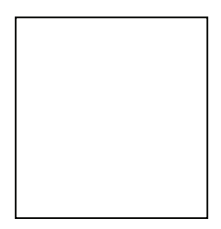

(b) Partially confined concrete

$+$
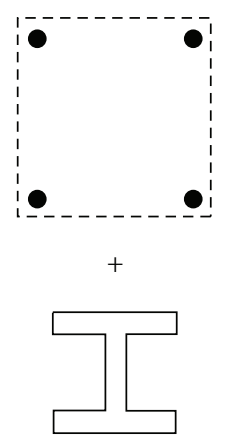

$\|$

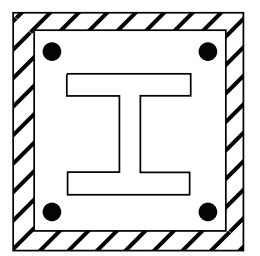

(e) Composite steel-concrete cross-section

FIGURE 2: FEM of cross-section.

and (d) the structural steel section, as indicated in Figure 2. The unconfined concrete was modeled by using a "thinwalled" box beam section with the inner wall of the box beam section coinciding with the centerline of the transverse tie reinforcement. The partially confined concrete was modeled by using a rectangular beam section with the outer edge of the rectangular beam section coinciding with the centerline of the transverse tie reinforcement and the inner edge of the box beam section. The longitudinal reinforcing bars were modeled by superimposing rebar elements within the rectangular beam section mesh. The structural steel section was modeled by using an I-beam section. Two different orientations of the I-beam section were used to model the major and minor axis bending problems. These beam sections and bar elements were superimposed at common node points in order to fully define the composite steelconcrete cross-section, as illustrated in Figure 2(e). The FEM software numerically integrated the cross-section to obtain the generalized force-strain (or moment-curvature) relationships. As the integration points were used to discretize a beam section and to define its mesh for numerical computations, an increase in integration points led to a denser mesh, resulting in a more accurate solution but a higher computational time. For this study, the number of integration points was increased substantially from the software default condition. The locations and number of integration points used are shown in Figure 3 for the four materials noted above.

A reinforced concrete cross-section was modeled like an identical composite cross-section from which the structural steel section had been removed (Figures 2(e)-2(d)). Hence, the foregoing modeling techniques described for the composite cross-sections apply to reinforced concrete crosssections as well.

The modeling of a reinforced concrete or a composite column (member) was accomplished by using a predefined three-dimensional three-node beam (space) element. The length of the column was divided into a number of segments, each representing a beam element. Each beam element was connected to adjacent elements at the two outer (common) node points. The central node point of the element was generated and used for integration purposes by the software. A discretized column subjected to symmetrical single curvature bending is illustrated in Figure 4(a). However, for the purpose of analysis, the symmetry about the midlength permitted the use of an equivalent "cantilever" column that was one-half the length of the original column, as illustrated in Figure 4(b), leading to a substantial saving in computational time. The boundary conditions at the top node of the column restrain movements along the $x$ and $z$-axes and rotation about the $y$-axis, whereas those at the bottom node of the column restrain movements along the $x_{-}^{-}, y_{-}$, and $z$-axes and the rotation about the $y$-axis (Figure $4(\mathrm{a})$ ). The node at the column midlength is restrained from movements along and rotations about the $y$ - and $z$-axes (Figure 4(b)). These restraints modeled the boundary conditions used in physical tests of column specimens analyzed in this study. To prevent the localization of element curvature, the finite element length was taken equal to or slightly greater than the overall depth of the crosssection in the plane of bending, as indicated in Figure 4(c). A column was loaded by applying a small axial load and/or a small bending moment at the top node (Figure 4(b)), reflecting the end eccentricity used in the physical test of the column specimen. The applied axial load and/or bending moment were then increased in increments of constant proportions, using a second-order analysis procedure, until failure occurred. The FEM failure strength of a column was defined as the peak strength reached on the momentdeflection response curve when the column was subjected to pure bending and as the peak strength reached on the loaddeflection response curve when the column was subjected to pure axial force or axial force combined with bending moment. For the analysis of columns subjected to pure axial load, an imperfection was added to the initially straight element model in order to ensure a smooth transition from column stability to column instability. This is due to the fact that a perfectly straight column subjected to pure axial 


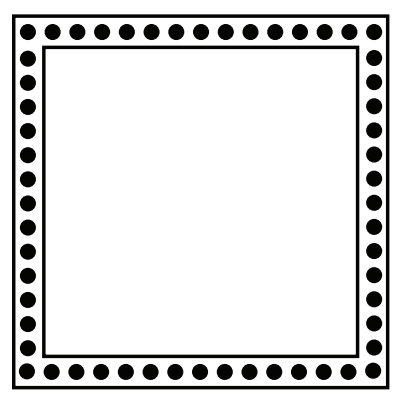

(a) Box section. Integration Points 15 each wall

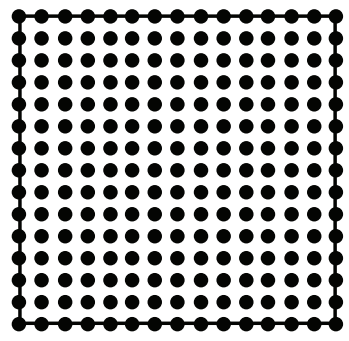

(b) Rectangular Section. Integration points $15 \times 15$

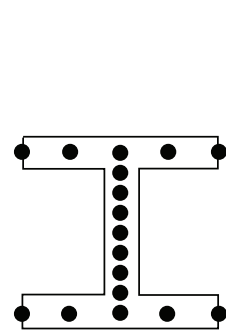

(c) I-Section. Integration points $5+9$ $+5$

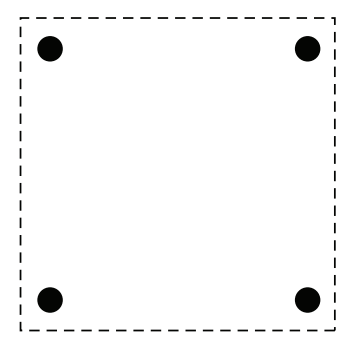

(d) Rebar Elements. Integration points 1 point/bar

FIGURE 3: Location of integration points used for FEM of cross-section.

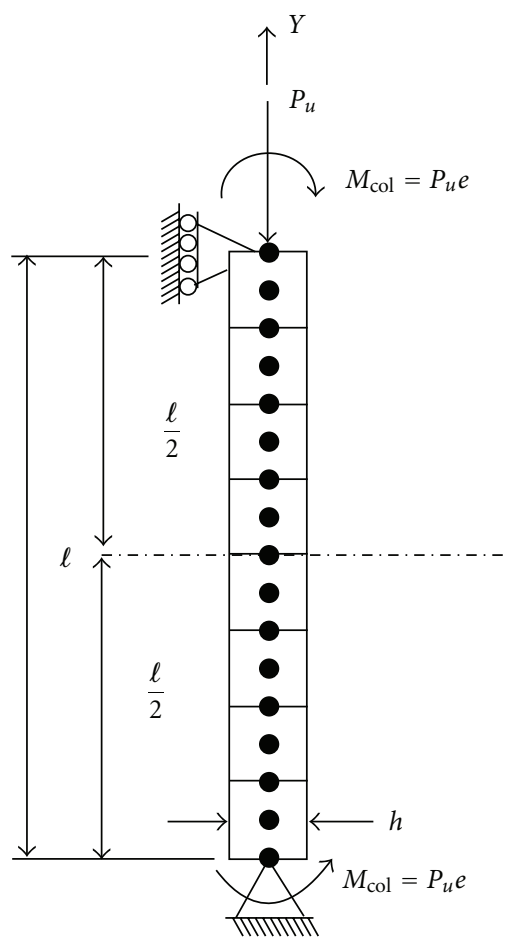

(a)

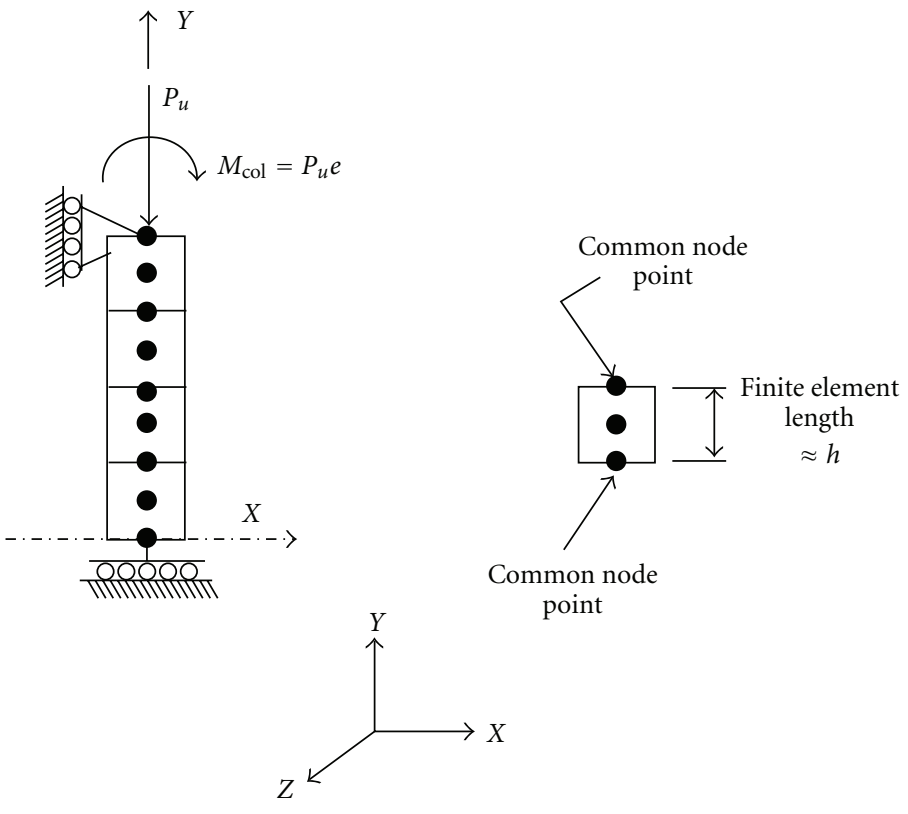

(b) (c)

FIGURE 4: FEM of column (member): (a) column in symmetrical single-curvature bending, (b) one-half length of column used for analysis, and (c) finite element segment.

load remains straight until the critical load is reached and then buckles suddenly. The large deflections associated with this sudden buckling could not be properly captured using the FEM software. In this study, the initial imperfection in pure compression members was introduced by applying a total transverse load equal to one percent of the self-weight of the column distributed uniformly over the entire column length.

The strain hardening of structural and reinforcing steels was neglected, as the data required for defining the strain hardening parts of stress-strain curves were not available from the literature for the most of column tests used in this study. Furthermore, Skrabek and Mirza [43] found that the strengths of composite columns subjected to end eccentricity ratios $(e / h) \leq 1.5$ were not significantly affected by the strain hardening of structural and reinforcing steels. With the exception of 16 composite columns that were subjected to pure bending $(e / h=\infty)$, all other composite and reinforced concrete columns used in this study had $e / h \leq 1.25$ (Tables 1 and 2), and neglecting the strain hardening of steel would not significantly affect their computed FEM strengths. Hence, the elastic-perfectly plastic stress-strain curves defined by measured values of yield strength and modulus of elasticity were used for structural steel section and reinforcing steel bars. These values of yield strength and modulus of elasticity were reported in individual studies taken from the literature. 


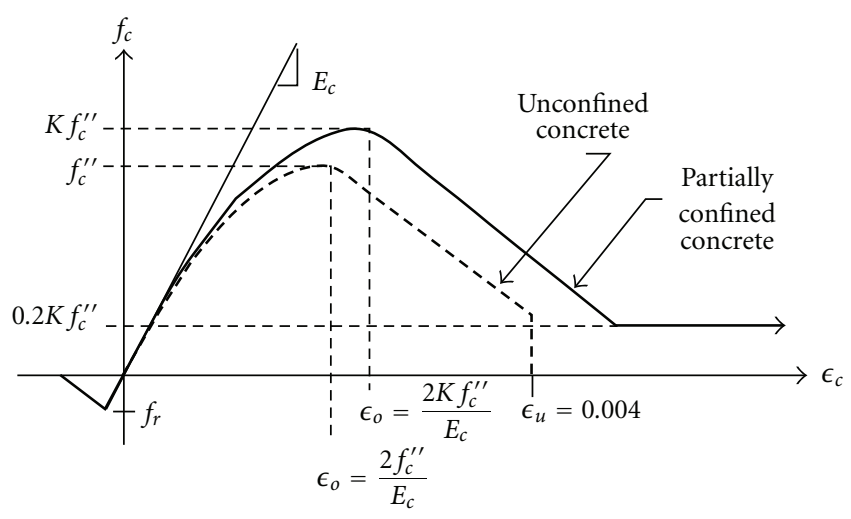

(a)

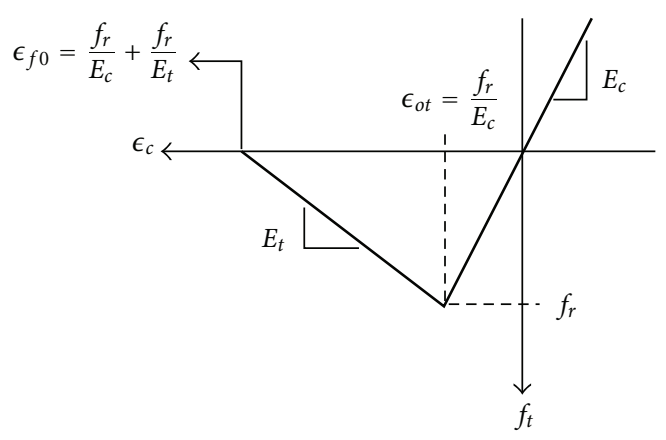

(b)

FIGURE 5: Schematic stress-strain curves used for FEM for concrete in (a) compression, and (b) tension.

The local buckling of the longitudinal reinforcing steel bars was not considered in the FEM analysis, since it was not clear from the published data whether such a failure occurred in the reported column tests used for this study. Hence, the local buckling of the longitudinal reinforcing bars was assumed to be resisted by the transverse tie reinforcement and the concrete inside the transverse ties. Note that if the local buckling of the longitudinal reinforcing bars were included in the analysis, the computed strengths would be lower for some of the column tests, resulting in slightly higher (better) average strength ratios than those reported in the later part of this paper.

The descriptions of both the unconfined and partially confined concretes in compression outside and inside the lateral ties, respectively, were taken from Park et al. [44], as illustrated schematically by the stress-strain curves in Figure 5(a). Second-order parabolas and straight lines represent the ascending parts up to the peak stress and the descending parts beyond the peak stress, respectively, in these curves. In Figure 5(a), $\epsilon_{o}$ is the concrete strain corresponding to the peak compressive stress $\left(f_{c}^{\prime \prime}\right.$ or $\left.K f_{c}^{\prime \prime}\right)$, $\epsilon_{u}$ is the ultimate compressive strain of unconfined concrete, and $K$ is a factor that represents the degree of concrete confinement provided by lateral ties. The concrete tensile stress-strain relationship used for the FEM of cross-sections was represented by a bilinear curve shown schematically in Figure 5(b). The ascending branch of this curve up to the peak stress $\left(f_{r}\right)$ was taken from Mirza and MacGregor [45], and the descending branch representing the "tension softening" after the cracking of concrete was taken from Bazant and Oh [46]. In Figure 5(b), $\epsilon_{o t}$ is the concrete strain corresponding to the peak tensile stress, $\epsilon_{f 0}$ is the strain where the tensile strength of concrete equals zero, and $E_{t}$ is the tension softening modulus of concrete taken equal to $0.48 E_{c} /\left(0.39+f_{r}\right) \mathrm{MPa}$. The compressive crushing and tensile cracking of concrete were, therefore, modeled by using the ultimate compressive strain $\epsilon_{u}$ and the descending parts of the stress-strain curves in Figure 5(a) and the ultimate tensile strain $\epsilon_{f 0}$ and the descending part of the stressstrain curve in Figure 5(b), respectively. In an attempt to construct a finite element model as complete as feasible, physical properties of concrete were modified to account for in-place conditions and rate of loading effects. Hence, the compressive strength $f_{c}^{\prime \prime}$, modulus of elasticity $E_{c}$, and modulus of rupture $f_{r}$ used for the concrete stress-strain curves in Figure 5 were computed from (3), which were taken from Mirza et al. [40]

$$
\begin{gathered}
f_{c}^{\prime \prime}=0.97 f_{c}^{\prime}\left[0.89\left(1+0.08 \log _{10}\left(\frac{0.97 f_{c}^{\prime}}{0.0069 t}\right)\right)\right] \\
E_{c}=5015 \sqrt{0.97 f_{c}^{\prime}}\left[1.16-0.08 \log _{10}(t)\right], \\
f_{r}=0.69 \sqrt{0.97 f_{c}^{\prime}}\left[0.96\left(1+0.11 \log _{10}\left(\frac{0.69 \sqrt{0.97 f_{c}^{\prime}}}{0.0069 t}\right)\right)\right],
\end{gathered}
$$

in which $f_{c}^{\prime}$ is the compressive strength of standard cylinders, in $\mathrm{MPa}$, as tested or computed from (2) and $t$ is the time, in seconds, taken by a column specimen to reach its failure load and was taken from the individual studies reported in the literature. In (3), the factor 0.97 applied to $f_{c}^{\prime}$ represents the effect of insitu conditions, including the size effect and curing under laboratory controls, and the term inside the square brackets represents the effect of rate of loading. Using (3) in conjunction with Figure 5 provided a more complete description of concrete stress-strain curves, and, perhaps, it was partly responsible for lower variations in FEM strengths than those in CSA strengths reported in a later section of this paper.

\section{FEM Strength Comparisons and Analyses}

The unfactored strengths of 354 reinforced concrete and 150 steel-concrete composite column specimens were calculated using the FEM procedure described in the foregoing section. The tested strengths were then divided by the computed unfactored strengths to obtain the nondimensionalized strength ratios. These strength ratios were taken as the ratios of bending moment strengths for $e / h=\infty$ and as the ratios of axial load strengths for $e / h<\infty$ and were used for statistical analyses and strength comparisons.

4.1. Comparisons of Tested and FEM Strengths. The strength ratio statistics for reinforced concrete column tests taken 
TABLe 3: Strength ratio statistics for reinforced concrete columns.

\begin{tabular}{|c|c|c|c|c|c|c|}
\hline \multirow{2}{*}{ Reference } & \multirow{2}{*}{$\ell / h$} & \multirow{2}{*}{$e / h$} & \multirow{2}{*}{$\rho^{\prime \prime}(\%)$} & \multirow{2}{*}{$n$} & \multicolumn{2}{|c|}{ Strength ratio statistics ${ }^{\mathrm{a}}$} \\
\hline & & & & & FEM & CSA \\
\hline Hognestad [19] & 7.5 & $0.00-1.25$ & 0.43 & 35 & $0.96(0.07)$ & $0.96(0.06)$ \\
\hline Ernst et al. [13] & $2.0-25.0$ & $0.00-0.38$ & 0.39 & 11 & $1.08(0.13)$ & $1.24(0.26)$ \\
\hline Viest et al. [31] & 8.0 & $0.25-0.76$ & 0.63 & 15 & $1.07(0.07)$ & $1.02(0.10)$ \\
\hline Gaede [15] & $29.4-35.4$ & $0.20-0.50$ & 0.12 & 8 & $0.80(0.06)$ & $0.92(0.13)$ \\
\hline Bresler [7] & $6.0-8.0$ & $0.50-1.00$ & 1.11 & 4 & $1.08(0.06)$ & $1.03(0.07)$ \\
\hline Bresler and Gilbert [8] & 7.5 & 0.00 & $0.46-0.70$ & 4 & $1.06(0.03)$ & $1.09(0.02)$ \\
\hline Chang and Ferguson [10] & 31.0 & $0.06-0.39$ & 0.21 & 6 & $0.93(0.06)$ & $1.27(0.22)$ \\
\hline Pfister [24] & $6.0-9.0$ & 0.00 & $0.04-0.53$ & 11 & $0.91(0.03)$ & $0.93(0.08)$ \\
\hline Roy and Sozen [27] & 5.0 & 0.00 & $1.99-2.24$ & 29 & $0.91(0.05)$ & $1.18(0.05)$ \\
\hline Todeschini et al. [30] & 8.1 & $0.00-0.50$ & 0.25 & 19 & $1.02(0.10)$ & $1.03(0.11)$ \\
\hline Hudson [20] & 8.0 & $0.00-0.33$ & $0.05-1.12$ & 60 & $1.02(0.15)$ & $1.05(0.13)$ \\
\hline Martin and Olivieri [22] & 40.0 & 0.00 & 0.36 & 2 & $0.97(0.04)$ & $2.20(0.08)$ \\
\hline Mehmel et al. [23] & $8.8-30.4$ & $0.08-1.00$ & $0.37-0.56$ & 12 & $0.99(0.08)$ & $1.13(0.20)$ \\
\hline Ramu et al. [25] & $14.4-28.9$ & $0.03-1.00$ & 0.47 & 6 & $0.92(0.04)$ & $1.17(0.26)$ \\
\hline Drysdale and Huggins [12] & 31.2 & 0.20 & 0.41 & 4 & $1.05(0.03)$ & $1.19(0.03)$ \\
\hline Goyal and Jackson [16] & $16.0-36.0$ & $0.17-0.50$ & $2.10-2.90$ & 26 & $0.83(0.07)$ & $0.97(0.08)$ \\
\hline Bunni [9] & $4.0-20.0$ & 0.00 & $1.03-1.58$ & 26 & $1.11(0.07)$ & $1.26(0.09)$ \\
\hline Green and Hellesland [17] & $15.0-15.2$ & $0.09-0.10$ & 0.25 & 2 & $0.98(0.01)$ & $1.10(0.06)$ \\
\hline Heimdahl and Bianchini [18] & $3.2-6.0$ & $0.21-1.06$ & 0.98 & 16 & $0.88(0.12)$ & $0.92(0.14)$ \\
\hline Sheikh and Uzumeri [29] & 6.4 & 0.00 & $0.63-2.31$ & 24 & $1.07(0.08)$ & $1.06(0.09)$ \\
\hline Scott et al. $[28]$ & 2.7 & $0.00-0.11$ & $1.82-1.93$ & 4 & $1.04(0.03)$ & $1.18(0.02)$ \\
\hline Razvi and Saatcioglu [26] & 2.9 & 0.00 & $1.21-2.51$ & 7 & $0.91(0.05)$ & $1.04(0.07)$ \\
\hline Cusson and Paultre [11] & 6.0 & 0.00 & $3.87-4.73$ & 2 & $1.07(0.01)$ & $1.34(0.03)$ \\
\hline Fang et al. [14] & 4.0 & 0.00 & $0.92-2.75$ & 13 & $0.98(0.08)$ & $1.15(0.08)$ \\
\hline Kim and Yang [21] & $3.0-30.0$ & 0.30 & 0.76 & 8 & $0.97(0.08)$ & $1.04(0.03)$ \\
\hline All Studies Combined & $2.0-40.0$ & $0.00-1.25$ & $0.04-4.73$ & 354 & $0.98(0.13)$ & $1.08(0.17)$ \\
\hline
\end{tabular}

a The statistics shown are the average values (and coefficients of variation in parentheses) of the ratios of tested to computed strengths. The computed strengths are those from FEM and CSA.

from individual studies and from all 25 studies combined are presented in Table 3. The individual studies included in the table are listed in the chronological order in which they appeared in the literature. The table shows that the FEM procedure produces an overall average strength ratio of 0.98 , a value close to unity, and a coefficient of variation of 0.13 when the data for 354 tests from all studies on reinforced concrete columns are combined. Table 3 also shows that for individual studies, the average strength ratios range from 0.80 to 1.11 and coefficients of variation range from 0.01 to 0.15 when the FEM strengths are compared to the tested strengths. For most individual studies, however, the average strength ratios are within $9 \%$ of unity with coefficients of variation less than or equal to 0.08 , as indicated by Table 3. This leads to the conclusion that the strength of reinforced concrete columns can be computed with a reasonable accuracy from the FEM procedure examined.

The strength ratio statistics for composite column tests taken from individual studies and from all 8 studies combined are presented in Table 4. Again, the individual studies included in the table are listed in the chronological order in which they appeared in the literature. A coefficient of variation of 0.17 in Table 4 for strength ratios of 150 tests from all studies combined indicates that the FEM procedure computes the column strength with an acceptable accuracy. However, an average strength ratio of 0.92 (Table 4) obtained for the same tests is lower than 1.0 and is a consequence of the data from Anslijn and Janss [32] falling significantly and consistently below unity. Of the 39 tests from Anslijn and Janss used in this study, 30 specimens were subjected to pure axial load, whereas the remaining nine were subjected to eccentric axial load with $e / h<0.2$. Hence, the strength of these 39 test specimens is susceptible to the concrete compressive strength. Anslijn and Janss reported the strength of 100-mm concrete cubes, and (1) and (2) were used to obtain equivalent standard cylinder strengths. These equations are empirical and could have introduced some margin of error into the conversion to cylinder strength. Furthermore, unintentional and/or accidental eccentricities during the testing process may have contributed to lower tested strengths for these columns. The specimens tested by Anslijn and Janss were $240 \mathrm{~mm} \times 240 \mathrm{~mm}$ or $320 \mathrm{~mm}$ $\times 210 \mathrm{~mm}$ in cross-section and were reinforced with very light transverse ties and longitudinal reinforcing bars $\left(\rho^{\prime \prime} \simeq\right.$ 0.002 and $\rho_{\mathrm{rs}}<0.008$ ). If the data from Anslijn and Janss [32] are excluded from the statistical analysis, the overall 
TABLE 4: Strength ratio statistics for composite columns.

\begin{tabular}{|c|c|c|c|c|c|c|}
\hline \multirow{2}{*}{ Reference } & \multirow{2}{*}{$\ell / h$} & \multirow{2}{*}{$e / h$} & \multirow{2}{*}{$\rho^{\prime \prime}(\%)$} & \multirow{2}{*}{$n$} & \multicolumn{2}{|c|}{ Strength ratio statistics ${ }^{\mathrm{a}}$} \\
\hline & & & & & FEM & CSA \\
\hline Stevens [38] & $7.0-18.2$ & $0.12-0.58$ & $0.00-0.28$ & 6 & $1.08(0.12)$ & $1.13(0.12)$ \\
\hline Procter [34] & $2.0-12.0$ & $0.00-0.80$ & 0.00 & 16 & $0.98(0.11)$ & $0.99(0.10)$ \\
\hline Anslijn and Janss [32] & $5.0-17.5$ & $0.00-0.19$ & $0.19-0.21$ & 39 & $0.75(0.13)$ & $1.13(0.27)$ \\
\hline Roderick and Loke [35] & $12.0-17.1$ & $0.00-0.21$ & 0.00 & 15 & $0.89(0.07)$ & $1.12(0.27)$ \\
\hline Morino et al. [33] & $5.8-28.9$ & $0.25-0.47$ & 0.25 & 16 & $0.98(0.09)$ & $1.04(0.10)$ \\
\hline Suzuki et al. [39] & $2.9-3.8$ & $0.00-1.06^{\mathrm{b}}$ & $0.07-2.91$ & 34 & $1.01(0.09)$ & $1.13(0.11)$ \\
\hline Roik and Mangerig [36] & $10.0-26.7$ & $0.10-0.50$ & 0.29 & 9 & $1.14(0.07)$ & $1.35(0.20)$ \\
\hline Roik and Schwalbenhofer [37] & $12.4-12.6$ & $0.00-0.71$ & 0.28 & 15 & $0.83(0.10)$ & $1.00(0.19)$ \\
\hline All studies combined & $2.0-28.9$ & $0.00-1.06^{\mathrm{b}}$ & $0.00-2.91$ & 150 & $0.92(0.17)$ & $1.10(0.21)$ \\
\hline $\begin{array}{l}\text { All studies other than Anslijn } \\
\text { and Janss }\end{array}$ & $2.0-28.9$ & $0.00-1.06^{\mathrm{b}}$ & $0.00-2.91$ & 111 & $0.98(0.13)$ & $1.09(0.18)$ \\
\hline
\end{tabular}

${ }^{a}$ The statistics shown are the average values (and coefficients of variation in parentheses) of the ratios of tested to computed strengths. The computed strengths are those from FEM and CSA.

${ }^{\mathrm{b}}$ Sixteen specimens were tested in pure bending $(e / h=\infty)$.

coefficient of variation decreases significantly from 0.17 to 0.13 , and the overall average strength ratio increases from 0.92 to 0.98 , a value close to unity (Table 4 ). This is not surprising, because the strength ratio statistics for almost all individual studies other than Anslijn and Janss are reasonably close to the overall values, as indicated by Table 4 . This leads to the conclusion that with an average strength ratio of 0.98 and coefficient of variation of 0.13 , the strength of composite columns can be computed also with a reasonable accuracy from the FEM procedure used.

For the purpose of comparison, the strength ratio cumulative frequency curve for reinforced concrete columns and that for composite columns were plotted on a normal probability scale. It was interesting to note that the shapes of the cumulative frequency curves for the two sets of data were very similar. In fact, when the data for composite columns taken from Anslijn and Janss [32] were excluded from the analysis, the two curves fell almost on top of one another with an average strength ratio of 0.98 and coefficient of variation of 0.13 in both cases. Hence, the FEM procedure used in this study computed the strength of both reinforced concrete and composite columns with a similar accuracy.

4.2. Effects of Major Variables. The effects of the end eccentricity ratio $e / h$, slenderness ratio $l / h$, transverse reinforcement (tie/hoop) volumetric ratio $\rho^{\prime \prime}$, and longitudinal reinforcing steel index $\rho_{\mathrm{rs}} f_{\mathrm{yrs}} / f_{c}^{\prime}$ on strength ratios for reinforced concrete columns are shown in Figures 6, 7, 8, and 9, respectively. Each of these figures was plotted from the data for all 354 column tests and illustrates the strength ratios computed from FEM. The strength ratios plotted in Figures $6,7,8$, and 9 are not significantly affected by any of the variables investigated. In fact, the plotted data are clustered almost equally on both sides of the line of equality (horizontal line of unity) over the entire range of each of the variables examined (Figures 6-9). Similar conclusions were reached from the plot prepared, but not shown here, for examining the effect of concrete strength $f_{c}^{\prime}$. This was

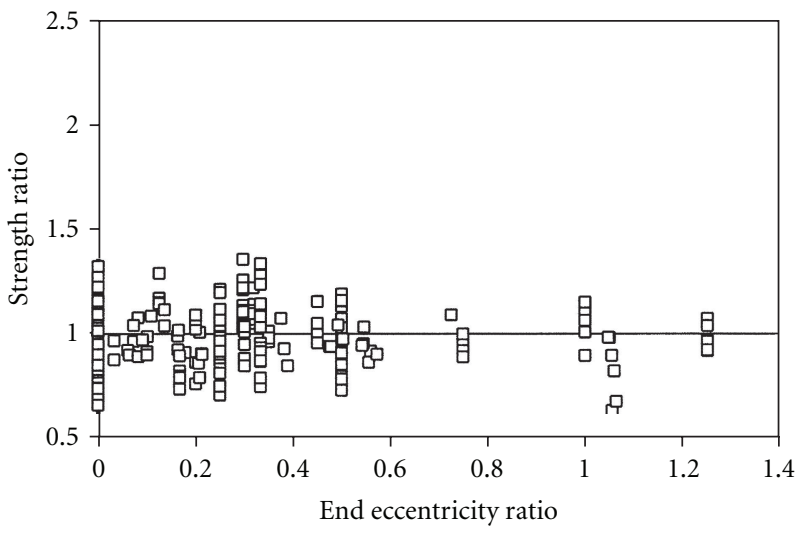

FIGURE 6: Effect of end eccentricity ratio $e / h$ on FEM strength ratios for reinforced concrete columns $(n=354)$.

expected, as the variables studied were explicitly or implicitly included in the FEM analysis, and this leads to the conclusion that the ratios of tested to FEM strengths for reinforced concrete columns are not affected by any of the variables examined in this study. This is remarkable in light of the fact that variability is an inherent feature of physical testing that tends to increase as data from several different sources are combined together.

The effects of the end eccentricity ratio $e / h$, slenderness ratio $\ell / h$, transverse reinforcement (tie/hoop) volumetric ratio $\rho^{\prime \prime}$, and structural steel index $\rho_{\mathrm{ss}} f_{\mathrm{yss}} / f_{c}^{\prime}$ on strength ratios for composite columns are shown in Figures 10, 11, 12 , and 13, respectively. Note that the data from Anslijn and Janss [32] were not included in Figures 10-13 for reasons described in the preceding section. Hence, each of these figures was plotted from the data for the remaining 111 column tests and illustrates the strength ratios computed from FEM. The strength ratios plotted in Figures 10-13 do not appear to be significantly affected by any of the variables investigated. In fact, the plotted data are clustered almost 


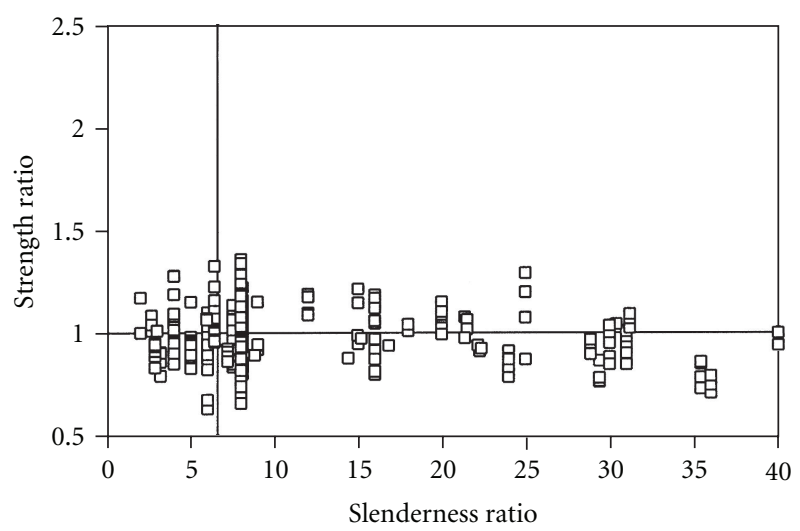

FIGURE 7: Effect of slenderness ratio $\ell / h$ on FEM strength ratios for reinforced concrete columns $(n=354)$.

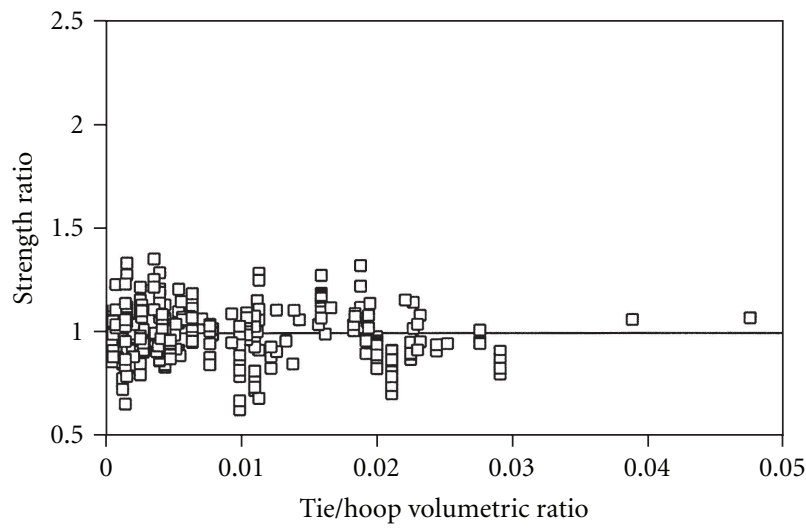

FIGURE 8: Effect of transverse reinforcement (tie/hoop) volumetric ratio $\rho^{\prime \prime}$ on FEM strength ratios for reinforced concrete columns $(n=354)$.

equally on both sides of the line of equality (horizontal line of unity) over the entire range of each of the variables examined (Figures 10-13). Similar conclusions were reached from the plot prepared, but not shown here, for examining the effect of concrete strength $f_{c}^{\prime}$. This was expected, because the variables studied were explicitly or implicitly included in the FEM analysis. Based on Figures 10-13 and the foregoing discussion, and recognizing the variations associated with physical testing itself, it is reasonable to conclude that the ratios of tested to FEM strengths for composite columns are also not affected by any of the variables examined in this study.

\subsection{Strength Ratio Statistics for Usual Columns. ACI 318 [6]} and CSA A23.3 [5] limit the slenderness ratio $\ell / h$ of pinended columns subjected to symmetrical single curvature bending, the type of columns used to examine FEM in this study, to a maximum value of 30 for reinforced concrete and slightly less than 30 for composite construction when such columns are designed using the ACI or CSA moment magnifier method. Similarly, ACI and CSA limit the $\ell / h$ ratio of columns to a minimum value of 3 . The European structural

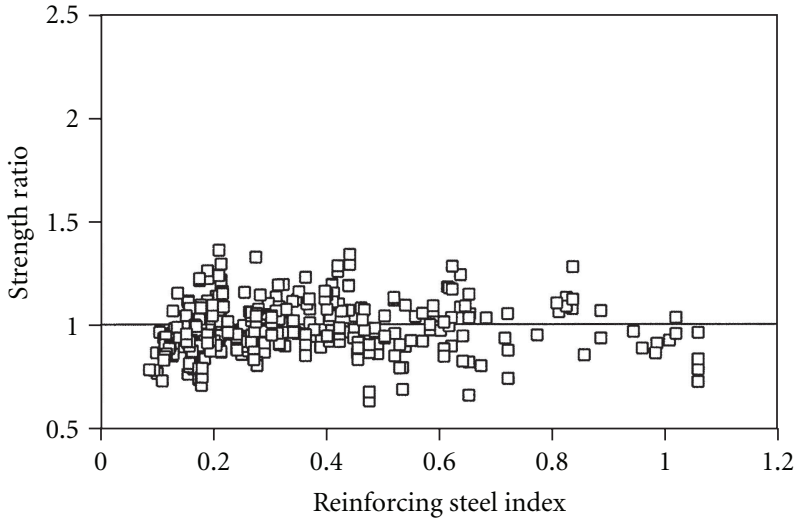

Figure 9: Effect of longitudinal reinforcing steel index $\rho_{\mathrm{rs}} f_{\mathrm{yrs}} / f_{c}^{\prime}$ on FEM strength ratios for reinforced concrete columns $(n=354)$.

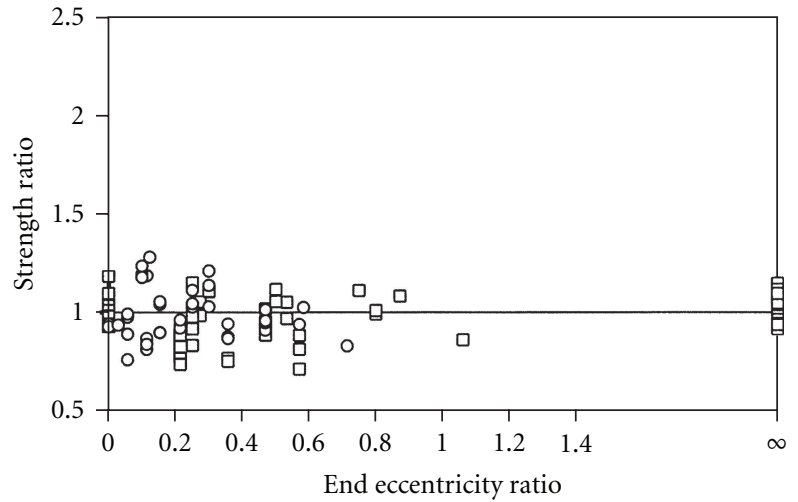

FIGURE 10: Effect of end eccentricity ratio $e / h$ on FEM strength ratios for composite columns $(n=111)$.

codes also place similar limits on the slenderness ratio of reinforced concrete and composite columns. Furthermore, columns in building structures are rarely subjected to pure axial force or pure bending; they are mostly subjected to axial load combined with bending moment [47]. Hence, the reinforced concrete and composite columns with $3<\ell / h<$ 30 and $0<e / h<\infty$ used in this study could be considered as "usual" columns.

The strength ratio statistics (average values and coefficients of variation) for the so-defined reinforced concrete, composite, and combined reinforced concrete and composite columns are given in Table 5. A comparison of these statistics clearly shows that the strength ratio statistics are about the same for all three groups of columns (average strength ratios of $1.00,0.98$, and 0.99 for reinforced concrete, composite, and combined reinforced concrete and composite columns, respectively, with a coefficient of variation of 0.13 for all three groups). The minimum and maximum strength ratios for reinforced concrete columns are 0.63 and 1.36, respectively, and those for composite columns are 0.71 and 1.28, respectively (footnotes of Table 5). Hence, the minimum and maximum values of strength ratios are 5.6 standard deviations apart for reinforced concrete columns and 4.5 standard deviations apart for composite columns, 
TABLE 5: Summary of strength ratio statistics for usual reinforced concrete and composite columns $(3<l / h<30$ and $0<e / h<\infty)$.

\begin{tabular}{|c|c|c|c|c|c|c|}
\hline \multirow{2}{*}{ Column type } & \multirow{2}{*}{$\ell / h$} & \multirow{2}{*}{$e / h$} & \multirow{2}{*}{$\rho^{\prime \prime}(\%)$} & \multirow{2}{*}{$n$} & \multicolumn{2}{|c|}{ Strength ratio statistics ${ }^{\mathrm{a}}$} \\
\hline & & & & & FEM & CSA \\
\hline Reinforced concrete $^{\mathrm{b}}$ & $3.0-30.0$ & $0.03-1.25$ & $0.1-2.9$ & 165 & $1.00(0.13)$ & $1.05(0.14)$ \\
\hline Composite $^{c}$ & $3.8-28.9$ & $0.03-1.06$ & $0.0-2.9$ & 67 & $0.98(0.13)$ & $1.09(0.19)$ \\
\hline Combined & $3.0-30.0$ & $0.03-1.25$ & $0.0-2.9$ & 232 & $0.99(0.13)$ & $1.06(0.16)$ \\
\hline
\end{tabular}

${ }^{a}$ The statistics shown are the average values (and coefficients of variation in parentheses) of the ratios of tested to computed strengths. The computed strengths are those from FEM and CSA.

${ }^{\mathrm{b}}$ The computed reinforced concrete column minimum (maximum) strength ratios are $0.63(1.36)$ for FEM and $0.63(1.70)$ for CSA, and $\rho_{\mathrm{rs}}=1.0 \%-6.9 \%$.

${ }^{\mathrm{c}}$ The computed composite column minimum (maximum) strength ratios are $0.71(1.28)$ for FEM and $0.78(1.87)$ for CSA, $\rho_{\mathrm{ss}}=2.7 \%-14.5 \%$, and $\rho_{\mathrm{rs}}=$ $0.0 \%-3.1 \%$.

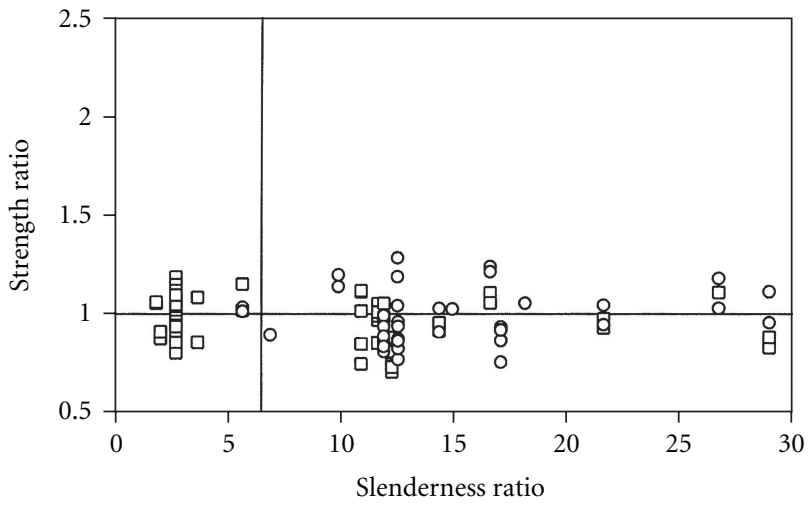

Figure 11: Effect of slenderness ratio $\ell / h$ on FEM strength ratios for composite columns $(n=111)$.

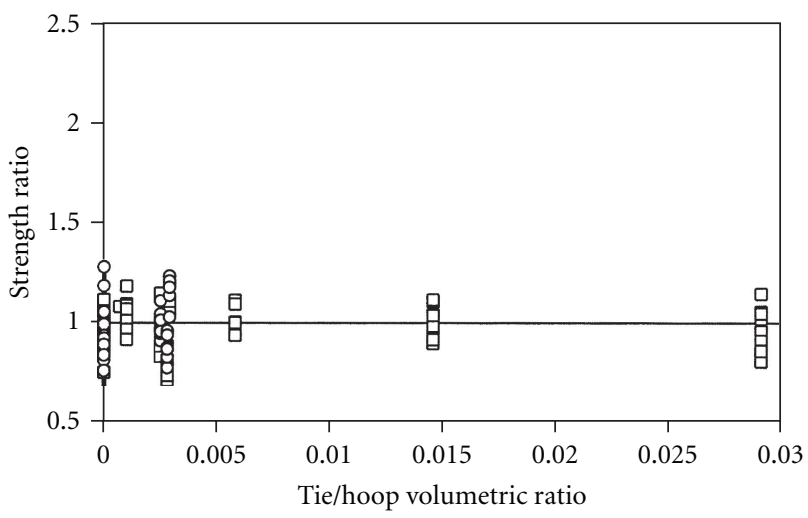

FIGURE 12: Effect of transverse reinforcement (tie/hoop) volumetric ratio $\rho^{\prime \prime}$ on FEM strength ratios for composite columns $(n=111)$.

indicating that the strength ratios for composite columns are subjected to a somewhat lower dispersion than those for reinforced concrete columns. This is expected, because the physical test strengths of composite columns are usually subjected to lower testing errors and/or in-batch variations than those of reinforced concrete columns. With an average strength ratio close to unity and a coefficient of variation of 0.13 for usual reinforced concrete and composite columns, Table 5 leads to the conclusion that the FEM procedure computes the strength of both groups of usual columns with a reasonable and similar accuracy.

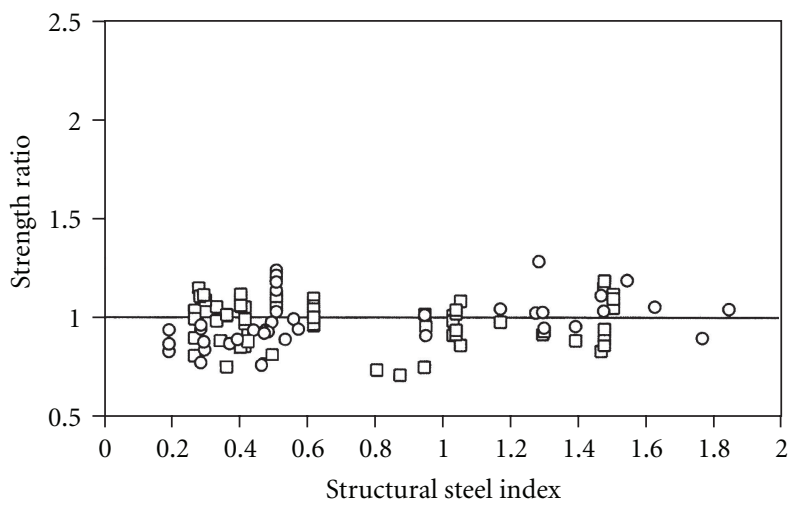

Figure 13: Effect of structural steel index $\rho_{\text {ss }} f_{\text {yss }} / f_{c}^{\prime}$ on FEM strength ratios for composite columns $(n=111)$.

\section{Comparison with CSA Strengths}

To establish the comparative accuracy of the FEM procedure, the computed FEM strength ratios were compared with the strength ratios calculated from the Canadian Standards Association (CSA) A23.3-04 procedure [5]. The CSA unfactored axial load strengths (or bending moment strengths in cases of pure bending) for test $e / h$ ratios were computed from the cross-section and column (member) axial force-bending moment strength interaction curves, similar to the ones shown in Figure 14. These strength interaction curves were generated for each test column used in this study and were based on the equilibrium of forces and the compatibility of strains. The material and member resistance factors were taken equal to 1.0 , and hence, the computed CSA strengths represent the unfactored strengths in this study. All other assumptions given in the CSA A23.3-04 [5] were used in computations of the CSA strengths, with the exception of the following CSA limitations that were ignored: (a) the upper limit on the axial load acting on a column, (b) the lower limits on cross-sectional areas of longitudinal reinforcing bars and transverse ties, (c) the upper limits on structural steel section and longitudinal reinforcing bar yield strengths, and (d) the upper limit on the slenderness ratio. Note that if these limits were included in the analysis, the computed CSA strengths would be lower for some of the column tests, resulting in slightly more conservative strength ratio statistics reported in the forthcoming paragraphs. 


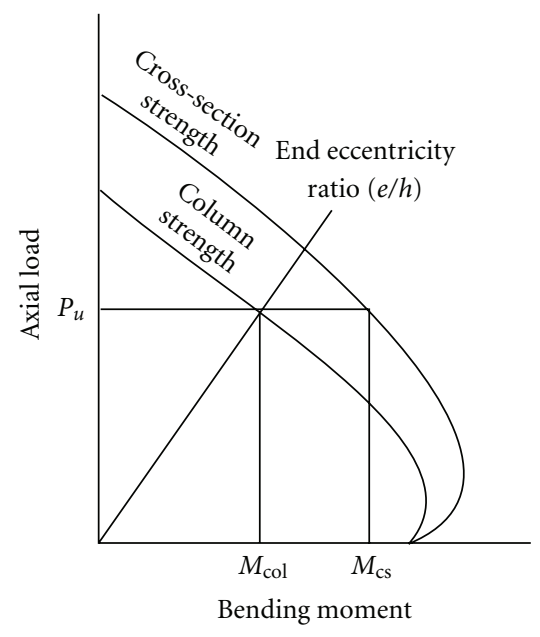

FIgURE 14: Schematic cross-section and column axial load-bending moment interaction curves used for CSA method.

For each test column, 102 points represented the crosssection strength interaction curve (Figure 14). The first point was determined for pure axial load strength $(e / h=0)$, the last point was computed for pure bending moment strength $(e / h=\infty)$, and the remaining 100 points were distributed uniformly along the interaction curve between these two points. The column (member) axial load-bending moment interaction curve (Figure 14) was developed from the cross-section strength interaction curve. The pure axial load strength of a column was first determined as the lesser of the cross-section pure axial load strength and the critical load of the pin-ended column (member). This established the maximum axial load that could be applied on the column. The cross-section bending moment resistance $\left(M_{\mathrm{cs}}\right)$ was then divided by the moment magnification factor to obtain the column bending moment resistance $\left(M_{\text {col }}\right)$ for each point on the cross-section interaction curve with axial load $\left(P_{u}\right)$ less than the column pure axial load strength, as indicated in Figure 14. The moment magnification factor was computed from the CSA equations using the pin-ended condition, symmetrical single-curvature bending, and shortterm loads.

For a short column $(\ell / r \leq 22$ for the type of columns studied), the column unfactored strength was taken equal to the cross-section strength for an $e / h$ equal to the test $e / h$, as permitted by CSA A23.3-04, where $r=$ radius of gyration of the reinforced concrete or composite cross-section. The unfactored strength of a slender column $(\ell / r>22$ for the type of columns studied) was determined from the column interaction curve, using the test $e / h$ ratio, as indicated in Figure 14.

The unfactored strengths of 354 reinforced concrete and 150 steel-concrete composite column specimens were calculated using the CSA procedure described in the foregoing paragraphs. The tested strengths were then divided by the computed unfactored strengths to obtain the nondimensionalized strength ratios. These strength ratios were taken as the ratios of bending moment strengths for $e / h=\infty$ and as the ratios of axial load strengths for $e / h<\infty$ and were used for comparison with the FEM strength ratios.

Strength ratio statistics for FEM and CSA procedures are compared for reinforced concrete and composite columns in Tables 3 and 4, respectively. These tables indicate that in almost all cases, the FEM procedure produces more "compact" statistics than does the CSA procedure in the sense that average strength ratios for FEM are closer to unity and are associated with lower coefficients of variation. This applies to statistics computed for individual studies as well as to overall statistics calculated when the data from all studies are combined, as indicated by Tables 3 and 4 : (a) average strength ratios $=0.80-1.11$ with coefficients of variation $=0.01-0.15$ for FEM and average strength ratios $=0.92-2.20$ with coefficients of variation $=0.02-0.26$ for CSA for individual studies on reinforced concrete columns, (b) overall average strength ratio $=0.98$ with coefficient of variation $=0.13$ for FEM and overall average strength ratio $=1.08$ with coefficient of variation $=0.17$ for CSA when data from all studies on reinforced concrete columns are combined, (c) average strength ratios $=0.83-1.14$ with coefficients of variation $=0.07-0.12$ for FEM and average strength ratios $=0.99-1.35$ with coefficients of variation $=0.10-0.27$ for CSA for individual studies on composite columns other than Anslijn and Janss, and (d) overall average strength ratio $=0.98$ with coefficient of variation $=0.13$ for FEM and overall average strength ratio $=1.09$ with coefficient of variation $=0.18$ for CSA when data from all studies on composite columns other than Anslijn and Janss are combined. For reasons described in an earlier section, the data from Anslijn and Janss [32] were not included in preparing the composite column statistics discussed above.

Plots prepared, but not shown here, to investigate the effects of variables indicate that when the CSA procedure is used, the end eccentricity ratio $e / h$, the transverse reinforcement (tie/hoop) volumetric ratio $\rho^{\prime \prime}$, and the slenderness ratio $\ell / h$ affect the reinforced concrete column strength ratios, whereas the end eccentricity ratio $e / h$ and the transverse reinforcement (tie/hoop) volumetric ratio $\rho^{\prime \prime}$ affect the composite column strength ratios. Furthermore, a comparison of these CSA plots with Figures 6-13 prepared for FEM strength ratios indicated that the CSA procedure produced significantly more scattered results than did the FEM method. Note that based on Figures 6-13, it was concluded previously that the ratios of tested to FEM strengths for reinforced concrete and composite columns are not affected by any of the variables examined in this study.

Table 5 compares the strength ratio statistics obtained for FEM and CSA procedures for usual reinforced concrete, composite, and combined reinforced concrete and composite columns. As noted earlier, the usual columns in this study were defined as those for which $3<\ell / h<30$ and $0<$ $e / h<\infty$. An examination of Table 5 and its footnotes leads to the following observations: (a) the FEM procedure produces strength ratio statistics (average values and coefficients of variation) more accurately than does the CSA procedure, (b) the computational accuracy of the FEM procedure is almost identical for both reinforced concrete and composite columns, whereas the CSA procedure produces significantly 


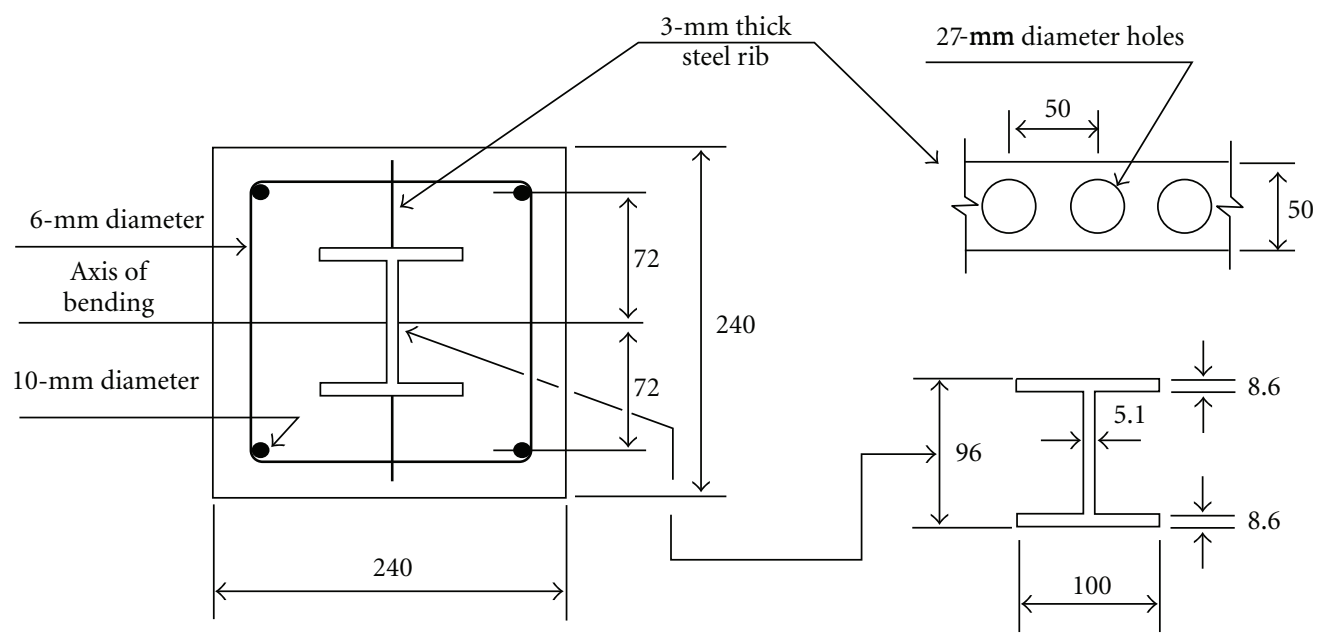

Figure 15: Cross-section details of Specimens RHB-1, RHB-3, and RHB-4A used for comparison of load-deflection behavior (dimensions are in $\mathrm{mm})$.

different statistics for reinforced concrete and composite columns, and (c) the minimum and maximum strength ratios for CSA are farther apart than those for FEM (footnotes of Table 5), confirming earlier observations that the FEM procedure produces less variable results than does the CSA method.

From Tables 3-5 and the foregoing discussion, it is reasonable to conclude that the FEM procedure computes the strength of reinforced concrete and composite steel-concrete columns more accurately than does the CSA procedure. This comment also applies to ACI 318-08 [6], as the column design requirements of ACI 318-08 are very similar to those of CSA A23.3-04.

\section{Comparison of Load-Deflection Behavior}

Computed load-deflection curves for three slender $(\ell / h=$ 16.7) composite column specimens based on the FEM procedure described in a previous section are reported here. Details of Specimens RHB-1, RHB-3, and RHB-4A, tested by the author and reported in an earlier study [48] are given in Figure 15. These specimens were chosen because the complete information required for computing loaddeflection curves based on the FEM procedure was easily available. The loading system consisted of concentric axial loads and a pair of transverse loads acting simultaneously on pin-ended specimens, producing a constant applied axial load over the entire 4000-mm length and a region of maximum applied bending moment over the central 1000-mm length of the column. Since the specimens were cast and tested horizontally, they were also subjected to a uniformly distributed transverse load due to the self-weight of the specimen. Hence, the maximum first-order bending moment occurred at the column midlength, which was also the location where the failure took place in all specimens. The ratio of transverse to axial loads was kept constant at all stages of loading for a given specimen but varied from specimen to specimen. The loads produced single-curvature bending in all specimens with bending moment acting about the major axis of the steel section.

The column specimens had identical material and geometric properties with the exception of slight unintentional variations in the concrete cylinder strength (27.2, 27.7, and 25.1 MPa for RHB-1, RHB-3, and RHB-4A, resp.) and intentional variations in the external (first-order) eccentricity at the failure section $(39.6,105.6$, and $370.8 \mathrm{~mm}$ for RHB-1, RHB-3, and RHB-4A, resp.). Hence, the first-order eccentricity at the failure section was the only variable used for these columns, and its range from 39.6 to $370.8 \mathrm{~mm}$ covered almost the entire practical range of the axial load-bending moment interaction diagram. As shown in Figure 15, ribs were welded to both sides of the steel section to enhance the interconnection between the steel section and the surrounding concrete. The structural steel ratio $\rho_{\text {ss }}$ was $4.2 \%$ with the yield strength $f_{\text {yss }}=293.4 \mathrm{MPa}$. The longitudinal reinforcing steel ratio $\rho_{\mathrm{rs}}$ and the transverse reinforcement (tie/hoop) volumetric ratio $\rho^{\prime \prime}$ were $0.55 \%$ and $0.25 \%$, respectively, with the yield strength $f_{\mathrm{yrs}}=$ 565.0 MPa. The transverse tie spacing was kept at $150 \mathrm{~mm}$ on centers.

In Figures 16(a), 16(b), and 16(c), applied transverse loads $(V)$ are plotted against the transverse midlength deflections $\left(\Delta_{m}\right)$ for Specimens RHB-1, RHB-3, and RHB$4 \mathrm{~A}$, respectively. In these figures, load-deflection responses measured from the physical tests are compared to those computed from the FEM procedure. These plots indicate an excellent agreement between experimental and FEM results for all three columns, which were tested with widely different levels of first-order eccentricities. Hence, the FEM procedure used in this study computes the entire load-deflection behavior with a reasonable accuracy and further reinforces the observations and/or conclusions reached earlier. 


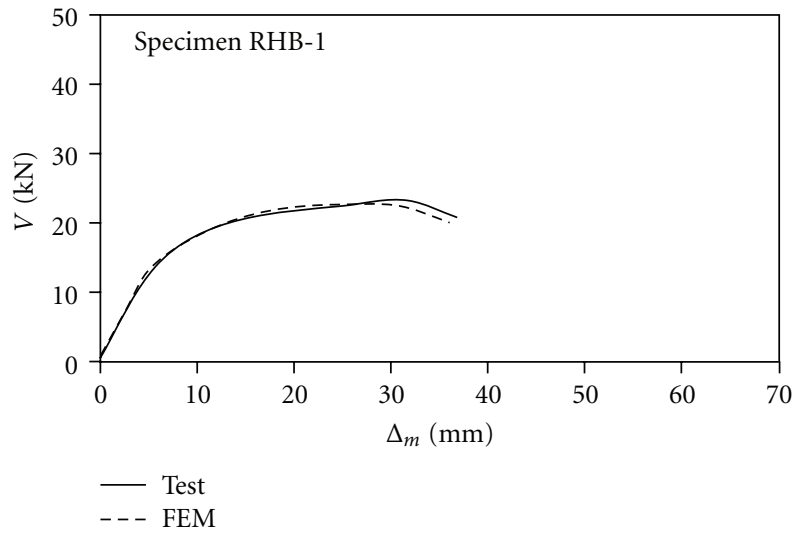

(a)

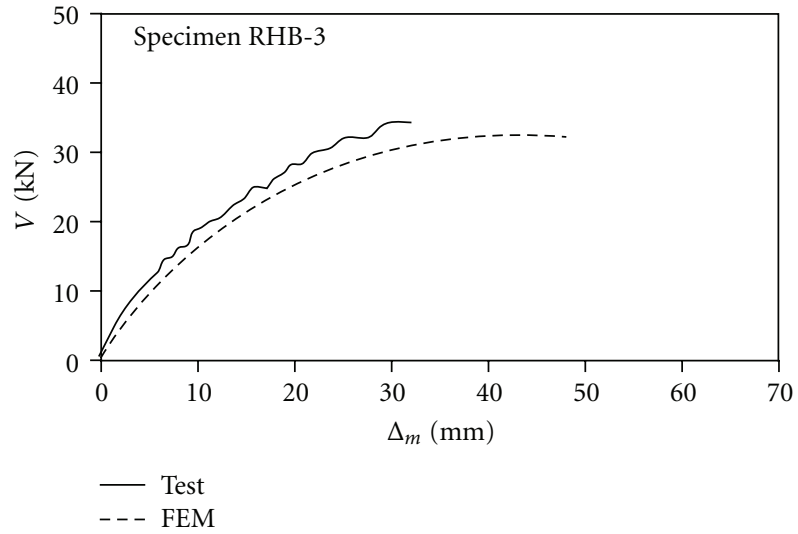

(b)

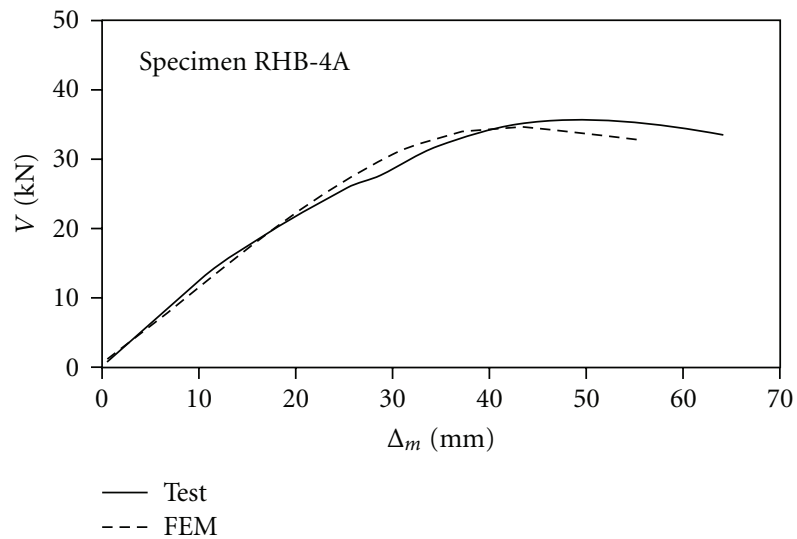

(c)

Figure 16: Comparison of load-deflection curves computed from FEM with those measured from physical tests: (a) Specimen RHB-1, (b) Specimen RHB-3, and (c) Specimen RHB-4A.

\section{Practical Application}

This paper provides a critical review of the FEM and CSA procedures used for computing the strength and related strength statistics of structural concrete columns. The evaluations and comparisons presented in the paper provide guidance for the reliability of FEM and CSA methods. This information will be helpful to structural engineers in making informed decisions when using FEM or CSA as a design tool.

Note that for the purpose of evaluating the computational accuracy of the FEM procedure, the strength ratios and load-deflection curves presented in this paper were based on unfactored computed strengths to which no material and/or member resistance factors were applied. However, when the FEM procedure is used for design, all appropriate material and/or member resistance factors specified by a relevant structural code of practice must be applied, because these factors along with load factors are intended to manage the probability of understrength due to variations in constituent material strengths and geometric imperfections among other factors, the probability of overloading caused by variations in loads and load combinations among other factors, or both.

\section{Summary and Conclusions}

The comparisons of physical test strengths of 504 rectangular reinforced concrete and composite column specimens taken from the literature with the strengths of the same columns calculated from a nonlinear FEM procedure and from the CSA method are presented in this paper. Of these, 354 were reinforced concrete columns, and the remaining 150 were composite columns in which steel sections were encased in concrete. The columns were constructed using normaldensity normal-strength concrete $\left(f_{c}^{\prime}=17-57 \mathrm{MPa}\right)$ and were tied, pin ended at both ends, and subjected to shortterm loads producing pure axial force, axial force combined with equal and opposite end bending moments, or pure bending moment.

The strength comparisons and statistical analyses presented in this paper show that the strength of reinforced concrete and composite columns can be computed with a reasonable accuracy using the FEM procedure examined. They also indicate that the ratios of the tested to FEM strengths are not affected by any of the variables investigated, which included the concrete strength $f_{c}^{\prime}$, the end eccentricity ratio $e / h$, the slenderness ratio $l / h$, the longitudinal reinforcing 
steel index $\rho_{\mathrm{rs}} f_{\mathrm{yrs}} / f_{c}^{\prime}$ for reinforced concrete columns or the structural steel index $\rho_{\text {ss }} f_{\text {yss }} / f_{c}^{\prime}$ for composite columns, and the transverse reinforcement (tie/hoop) volumetric ratio $\rho^{\prime \prime}$. The comparisons and analyses further establish that the FEM procedure produces comparable strength ratio statistics (average value $\simeq 1.0$ and coefficient of variation $=13 \%$ ) for all reinforced concrete and composite columns examined as well as for usual reinforced concrete and composite columns for which $3<e / h<30$ and $0<e / h<\infty$. Finally, the comparisons between the CSA and FEM strength ratios clearly show that the FEM procedure computes the strength of reinforced concrete and composite columns with considerable more accuracy than does the CSA procedure. The results of the study are limited to columns subjected to short-term loads.

\section{Notation}

$A_{t}$ : Area of cross-section of a tie/hoop bar

$b$ : Overall width of column cross-section taken parallel to axis of bending

$b^{\prime \prime}$ : Outside width of ties/hoops

$d^{\prime \prime}$ : Outside depth of ties/hoops

$E_{c}$ : Modulus of elasticity of concrete

$E_{t}$ : Tension softening modulus of concrete used for FEM

$e$ : $\quad$ Eccentricity of axial load at column ends (first-order eccentricity)

$e / h$ : End eccentricity ratio

$f_{c}, f_{t}$ : Compressive, tensile stress of concrete that corresponds to given value of strain

$f_{c}^{\prime}$ : Concrete strength from standard cylinder tests or equivalent cylinder strength from cube tests

$f_{c}^{\prime \prime}$ : Compressive strength of unconfined concrete used for FEM

$f_{r}$ : Modulus of rupture of concrete used for FEM

$f_{\mathrm{yrs}}$ : Yield strength of reinforcing steel bars

$f_{\text {yss }}$ : Yield strength of structural steel

$h$ : Overall depth of column cross-section taken perpendicular to axis of bending

$K$ : $\quad$ Factor representing concrete confinement provided by lateral ties used for FEM

$\ell$ : Column length

$\ell / h$ : Slenderness ratio

$M_{\text {col }}$ : Bending moment strength of column (member) at axial load equal to $P_{u}$

$M_{\mathrm{cs}}$ : Bending moment strength of column cross-section at axial load equal to $P_{u}$

$n: \quad$ Number of test specimens

$P_{u}: \quad$ Axial load strength

$r$ : Radius of gyration of cross-section

$s_{h}$ : $\quad$ Spacing of transverse ties/hoops

$V: \quad$ Applied transverse load (used for Specimens RHB-1, RHB-3, RHB-4A)

$\Delta_{m}$ : Transverse (lateral) deflection of column at midheight or midlength

$\epsilon_{c}$ : Strain in concrete $\epsilon_{f 0}$ : Strain where tensile strength of concrete equals zero used for FEM

$\epsilon_{o}, \epsilon_{o t}:$ Compressive, tensile strain in concrete at peak stress used for FEM

$\epsilon_{u}$ : $\quad$ Ultimate compressive strain of unconfined concrete taken as 0.004 for FEM

$\rho^{\prime \prime}: \quad$ Tie/hoop volumetric ratio taken equal to $2\left(b^{\prime \prime}+d^{\prime \prime}\right) A_{t} / b^{\prime \prime} d^{\prime \prime} s_{h}$

$\rho_{\mathrm{rs}}$ : Ratio of cross-sectional area of longitudinal reinforcing bars to gross area of cross-section

$\rho_{\text {ss }}$ : Ratio of cross-sectional area of structural steel section to gross area of concrete cross-section

$\rho_{\mathrm{rs}} f_{\mathrm{yrs}} / f_{c}^{\prime}$ : Longitudinal reinforcing steel index

$\rho_{\text {ss }} f_{\text {yss }} / f_{c}^{\prime}$ : Structural steel index.

\section{Acknowledgments}

The author acknowledges the financial support provided by the Natural Sciences and Engineering Research Council of Canada. The author also wishes to thank Edward A. Lacroix for the computing support.

\section{References}

[1] R. W. Furlong, "Rational analysis of multistory concrete structure," ACI Concrete International, vol. 3, no. 6, pp. 29-35, 1981.

[2] L. G. Griffis, "Some design considerations for compositeframe structures," Engineering Journal, vol. 23, no. 2, pp. 5964, 1986

[3] ABAQUS, Version 5.4 Theory Manual, Hibbitt, Karlsson, and Sorensen Inc., Pawtucket, RI, USA, 1994.

[4] ABAQUS, Version 5.4 User's Manual, Hibbitt, Karlsson, and Sorensen Inc., Pawtucket, RI, USA, 1994.

[5] CSA, Design of concrete structures-standard CSA A23.3-04, Canadian Standards Association, Rexdale, Ont, Canada, 2004.

[6] ACI, Building Code Requirements for Structural Concrete (ACI 318-08) and Commentary (ACI 318R-08), American Concrete Institute, Farmington Hills, Mich, USA, 2008.

[7] B. Bresler, "Design criteria for reinforced columns under axial load and biaxial bending," American Concrete Institute Journal, vol. 57, no. 5, pp. 481-490, 1960.

[8] B. Bresler and P. H. Gilbert, "Tie requirements for reinforced concrete columns," American Concrete Institute Journal, vol. 58, no. 5, pp. 555-569, 1961.

[9] N. G. Bunni, "Rectangular ties in reinforced concrete columns," in Reinforced Concrete Columns, ACI Special Publication SP-50, pp. 193-210, American Concrete Institute, Detroit, Mich, USA, 1975.

[10] W. F. Chang and P. M. Ferguson, "Long hinged reinforced concrete columns," American Concrete Institute Journal, vol. 60, no. 1, pp. 1-25, 1963.

[11] D. Cusson and P. Paultre, "High-strength concrete columns confined by rectangular ties," Journal of Structural Engineering, vol. 120, no. 3, pp. 783-804, 1994.

[12] R. G. Drysdale and M. W. Huggins, "Sustained biaxial load on slender concrete columns," ASCE Journal of the Structural Division, vol. 97, no. 5, pp. 1423-1443, 1971.

[13] G. C. Ernst, J. J. Hromadik, and A. R. Riveland, "Inelastic buckling of plain and reinforced concrete columns, plates and 
shells," Engineering Experiment Station Bulletin 3, University of Nebraska, Lincoln, Neb, USA, 1953.

[14] I. K. Fang, K. C. Hong, and J. Y. Wu, "Strength and ductility of high strength tied columns," Proceedings of the National Science Council, Republic of China, vol. 18, no. 1, pp. 63-74, 1994.

[15] K. Gaede, "Knicken von stahlbetonstäben unter kurz- und langzeitbelastung," in Deutscher Ausschuss für Stahlbeton Heft, vol. 129, Wilhelm Ernst \& Sohn, Berlin, Germany, 1958.

[16] B. B. Goyal and N. Jackson, "Slender concrete columns under sustained load," ASCE Journal of the Structural Division, vol. 97, no. 11, pp. 2729-2750, 1971.

[17] R. Green and J. Hellesland, "Repeated loading tests of reinforced concrete columns," in Reinforced Concrete Columns, ACI Special Publication SP-50, pp. 67-91, American Concrete Institute, Detroit, Mich, USA, 1975.

[18] P. D. Heimdahl and A. C. Bianchini, "Ultimate strength of biaxially eccentrically loaded concrete columns reinforced with high-strength steel," in Reinforced Concrete Columns, ACI Special Publication SP-50, pp. 93-117, American Concrete Institute, Detroit, Mich, USA, 1975.

[19] E. Hognestad, "A study of combined bending and axial load in reinforced concrete members," in Engineering Experiment Station Bulletin, vol. 399, University of Illinois, Urbana, Ill, USA, 1951.

[20] F. M. Hudson, "Reinforced concrete columns: effects of lateral tie spacing on ultimate strength," in Reinforced Concrete Columns, ACI Special Publication SP-13, pp. 235-244, American Concrete Institute, Detroit, Mich, USA, 1965.

[21] J. K. Kim and J. K. Yang, "Buckling behaviour of slender highstrength concrete columns," Engineering Structures, vol. 17, no. 1, pp. 39-51, 1995.

[22] I. Martin and E. Olivieri, "Tests of slender reinforced concrete columns bent in double curvature," in Reinforced Concrete Columns, ACI Special Publication SP-13, pp. 121-138, American Concrete Institute, Detroit, Mich, USA, 1965.

[23] A. Mehmel, H. Schwarz, K. H. Kasparek, and J. Makovi, "Tragverhalten ausmittig beanspruchter stahlbetondruckglieder," in Deutscher Ausschuss für Stahlbeton Heft, vol. 204, Wilhelm Ernst \& Sohn, Berlin, Germany, 1969.

[24] J. F. Pfister, "Influence of ties on behavior of reinforced concrete columns," American Concrete Institute Journal, vol. 61, no. 5, pp. 521-537, 1964.

[25] P. Ramu, M. Grenacher, M. Baumann, and B. Thürlimann, Versuche an Gelenkig Gelagerten Stahlbetonstützen unter Dauerlast, Institut für Baustatik, ETH, Zürich, Switzerland, 1969.

[26] S. R. Razvi and M. Saatcioglu, "Confinement of reinforced concrete columns with welded wire fabric," ACI Structural Journal, vol. 86, no. 5, pp. 615-623, 1989.

[27] H. E. H. Roy and M. A. Sozen, "Ductility of concrete," in Proceedings of ASCE-ACI International Symposium on Flexural Mechanics of Reinforced Concrete, pp. 213-235, American Society of Civil Engineers, Miami, Fla, USA, 1964.

[28] B. D. Scott, R. Park, and M. J. N. Priestley, "Stress-strain behavior of concrete confined by overlapping hoops at low and high strain rates," Journal of the American Concrete Institute, vol. 79, no. 1, pp. 13-27, 1982.

[29] S. A. Sheikh and S. M. Uzumeri, "Strength and ductility of tied concrete columns," ASCE Journal of the Structural Division, vol. 106, no. 5, pp. 1079-1102, 1980.
[30] C. E. Todeschini, A. C. Bianchini, and C. E. Kesler, "Behavior of concrete columns reinforced with high-strength steels," American Concrete Institute Journal, vol. 61, no. 6, pp. 701716, 1964.

[31] I. M. Viest, R. C. Elstner, and E. Hognestad, "Sustained load strength of eccentrically loaded short reinforced concrete columns," American Concrete Institute Journal, vol. 27, no. 7, pp. 727-755, 1956.

[32] R. Anslijn and J. Janss, "Le calcul des charges ultimes des colonnes métalliques enrobées de béton," Tech. Rep. MT89, CRIF, Brussels, Belgium, 1974.

[33] S. Morino, C. Matsui, and H. Watanabe, "Strength of biaxially loaded SRC columns," in Proceedings of Composite and Mixed Construction, C. W. Roeder, Ed., pp. 185-194, American Society of Civil Engineers, Seattle, Wash, USA, 1984.

[34] A. N. Procter, "Full size tests facilitate derivation of reliable design methods," Consulting Engineer, vol. 31, no. 8, pp. 5460, 1967.

[35] J. W. Roderick and Y. O. Loke, "Pin-ended composite columns bent about the minor axis," Tech. Rep. R-254, Sydney University Civil Engineering Laboratory, Sydney, Australia, 1974.

[36] K. Roik and I. Mangerig, "Experimentelle untersuchungen der tragfähigkeit von einbetonierten stahlprofilstützen unter besonderer berücksichtigung des langzeit verhaltens von beton," in Bericht zu P102, Studiengesellschaft für Anwendungstechnik von Eisen und Stahl e.V., Düsseldorf, Germany, 1987.

[37] K. Roik and K. Schwalbenhofer, "Experimentelle untersuchungen zum plastischen verhalten von verbundstützen," in Bericht zu P125, Studiengesellschaft für Anwendungstechnik von Eisen und Stahl e.V., Düsseldorf, Germany, 1988.

[38] R. F. Stevens, “The strength of encased stanchions," National Building Studies Research Paper no. 38, Ministry of Technology Building Station, London, England, 1965.

[39] T. Suzuki, K. Takiguchi, T. Ichinose, and T. Okamoto, "Effects of hoop reinforcement in steel and reinforced concrete composite sections," Bulletin of the New Zealand National Society for Earthquake Engineering, vol. 17, no. 3, pp. 198-214, 1984.

[40] S. A. Mirza, M. Hatzinikolas, and J. G. MacGregor, "Statistical descriptions of strength of concrete," ASCE Journal of the Structural Division, vol. 105, no. 6, pp. 1021-1037, 1979.

[41] V. V. Bolotin, Statistical Methods in Structural Mechanics, Holden-Day Inc., San Francisco, Calif, USA, 1969, Translated by S. Aroni.

[42] R. L’Hermite, Idées Actuelles sur la Technologie du Béton, La Documentation Technique du Bâtiment et des Travaux Publics, Paris, France, 1955.

[43] B. W. Skrabek and S. A. Mirza, "Strength reliability of short and slender composite steel-concrete columns," Civil Engineering Research Series Report CE-90-1, Lakehead University, Thunder Bay, Ontario, Canada, 1990.

[44] R. Park, M. J. N. Priestley, and W. D. Gill, "Ductility of squareconfined concrete columns," ASCE Journal of the Structural Division, vol. 108, no. 4, pp. 929-950, 1982.

[45] S. A. Mirza and J. G. MacGregor, "Slenderness and strength reliability of reinforced concrete columns," ACI Structural Journal, vol. 86, no. 4, pp. 428-438, 1989.

[46] Z. P. Bazant and B. H. Oh, "Deformation of progressively cracking reinforced concrete beams," Journal of the American Concrete Institute, vol. 81, no. 3, pp. 268-278, 1984. 
[47] S. A. Mirza and J. G. MacGregor, "Probabilistic study of strength of reinforced concrete members," Canadian Journal of Civil Engineering, vol. 9, no. 3, pp. 431-448, 1982.

[48] S. A. Mirza, V. Hyttinen, and E. Hyttinen, "Physical tests and analyses of composite steel-concrete beam-columns," Journal of Structural Engineering, vol. 122, no. 11, pp. 1317-1326, 1996. 

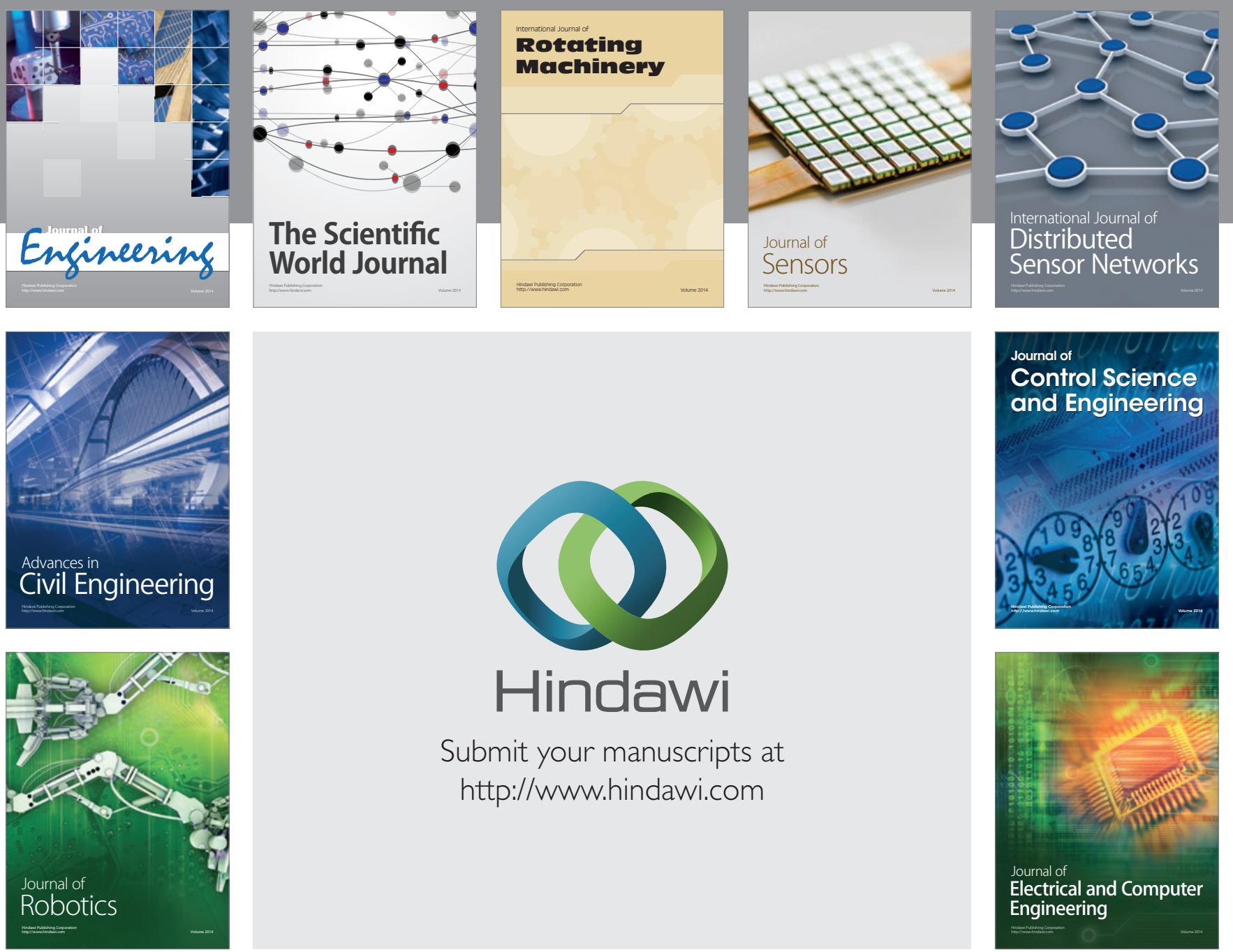

Submit your manuscripts at

http://www.hindawi.com
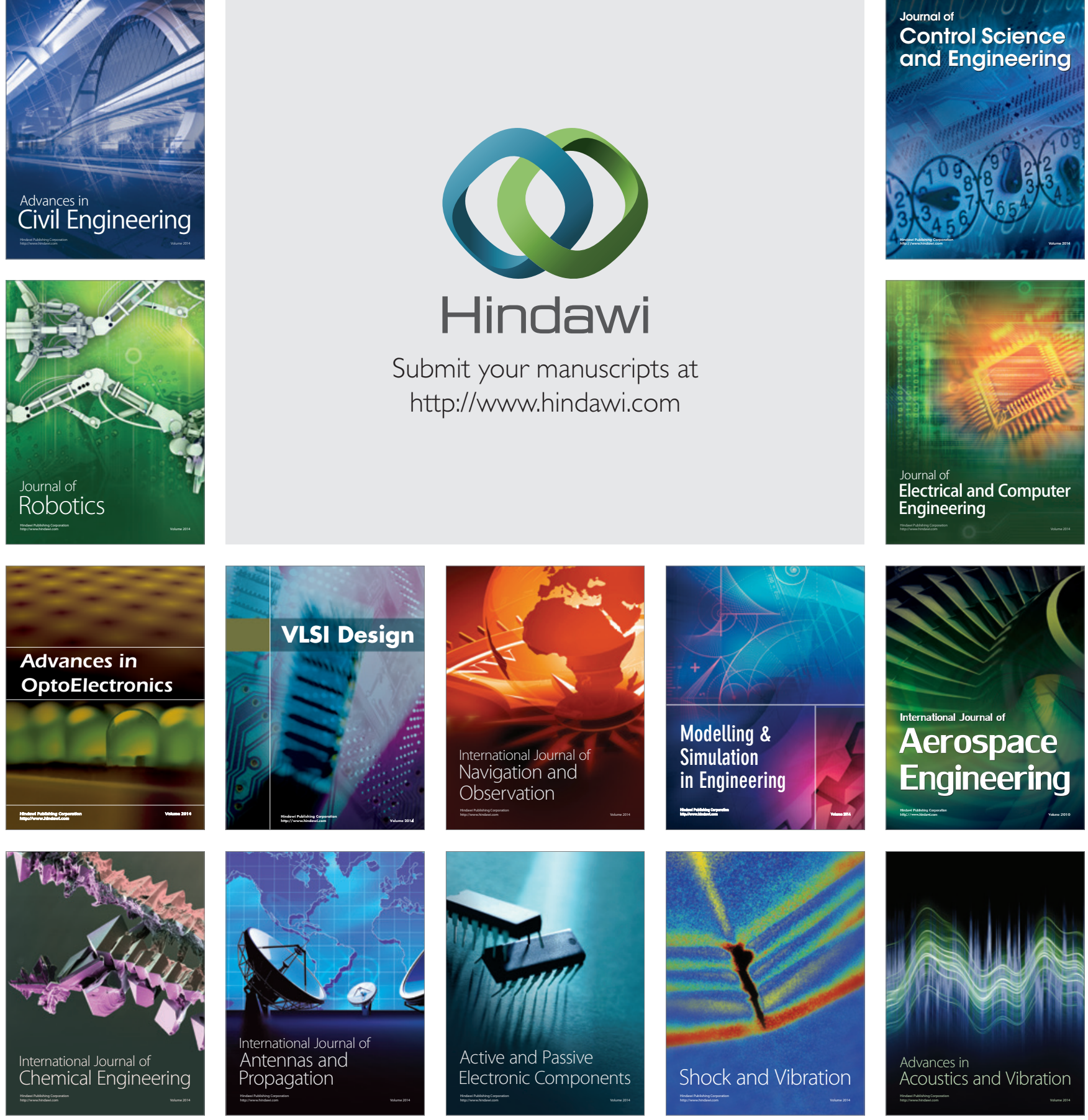